\title{
Comprehensive Estimates of Potential Synaptic Connections in Local Circuits of the Rodent Hippocampal Formation by Axonal-Dendritic Overlap
}

\author{
${ }^{\circledR}$ Carolina Tecuatl, ${ }^{\circledR}$ Diek W. Wheeler, ${ }^{\circledR}$ Nate Sutton, and Giorgio A. Ascoli \\ Center for Neural Informatics, Structures, \& Plasticity, Krasnow Institute for Advanced Study; and Bioengineering Department, Volgenau School of \\ Engineering, George Mason University, Fairfax, Virginia 22030-4444
}

A quantitative description of the hippocampal formation synaptic architecture is essential for understanding the neural mechanisms of episodic memory. Yet the existing knowledge of connectivity statistics between different neuron types in the rodent hippocampus only captures a mere $5 \%$ of this circuitry. We present a systematic pipeline to produce first-approximation estimates for most of the missing information. Leveraging the www.Hippocampome.org knowledge base, we derive local connection parameters between distinct pairs of morphologically identified neuron types based on their axonal-dendritic overlap within every layer and subregion of the hippocampal formation. Specifically, we adapt modern image analysis technology to determine the parcel-specific neurite lengths of every neuron type from representative morphologic reconstructions obtained from either sex. We then compute the average number of synapses per neuron pair using relevant anatomic volumes from the mouse brain atlas and ultrastructurally established interaction distances. Hence, we estimate connection probabilities and number of contacts for $>1900$ neuron type pairs, increasing the available quantitative assessments more than 11 -fold. Connectivity statistics thus remain unknown for only a minority of potential synapses in the hippocampal formation, including those involving long-range $(23 \%)$ or perisomatic $(6 \%)$ connections and neuron types without morphologic tracings $(7 \%)$. The described approach also yields approximate measurements of synaptic distances from the soma along the dendritic and axonal paths, which may affect signal attenuation and delay. Overall, this dataset fills a substantial gap in quantitatively describing hippocampal circuits and provides useful model specifications for biologically realistic neural network simulations, until further direct experimental data become available.

Key words: CA1; CA3; dentate gyrus; entorhinal cortex; interneuron; network

\section{Significance Statement}

The hippocampal formation is a crucial functional substrate for episodic memory and spatial representation. Characterizing the complex neuron type circuit of this brain region is thus important to understand the cellular mechanisms of learning and navigation. Here we present the first numerical estimates of connection probabilities, numbers of contacts per connected pair, and synaptic distances from the soma along the axonal and dendritic paths, for more than 1900 distinct neuron type pairs throughout the dentate gyrus, CA3, CA2, CA1, subiculum, and entorhinal cortex. This comprehensive dataset, publicly released online at www. Hippocampome.org, constitutes an unprecedented quantification of the majority of the local synaptic circuit for a prominent mammalian neural system and provides an essential foundation for data-driven, anatomically realistic neural network models.

Received May 14, 2020; revised Oct. 19, 2020; accepted Dec. 13, 2020.

Author contributions: C.T., D.W.W., and G.A.A. designed research; C.T., D.W.W., and G.A.A. performed research; C.T., D.W.W., and N.S. contributed unpublished reagents/analytic tools; C.T., D.W.W., and G.A.A. analyzed data; C.T. wrote the first draft of the paper; C.T., D.W.W., N.S., and G.A.A. edited the paper; C.T., D.W.W., N.S., and G.A.A. wrote the paper.

This work was supported in part by National Institutes of Health Grants R01NS39600 and U01MH114829. C.T. was supported by Consejo Nacional de Ciencia y Tecnología, México Fellowship 253060 (allowing this project to start during her PhD training). We thank Keivan Moradi, Siva Venkadesh, Jeffrey D. Kopsick, and Nikhil Koneru for help and feedback.

The authors declare no competing financial interests.

Correspondence should be addressed to Giorgio A. Ascoli at ascoli@gmu.edu.

https://doi.org/10.1523/JNEUROSCI.1193-20.2020

Copyright $\odot 2021$ the authors

\section{Introduction}

The hippocampal formation is a group of cytoarchitectonically distinct adjoining subregions linked by a largely unidirectional neuronal pathway (Andersen et al., 1971): the dentate gyrus (DG), cornu ammonis (CA3, CA2, and CA1), subiculum (Sub), and entorhinal cortex (EC). Like other cortical areas, the hippocampus is characterized by a high degree of neuronal interconnectivity and considerable cellular diversity. A single neuron is typically targeted by thousands of afferents from multiple neuron types, whereas the efferent output of an individual neuron contacts thousands 
of postsynaptic neurons of multiple types (Halasy et al., 1996; Ali et al., 1999; van Strien et al., 2009).

Proper hippocampus functioning requires each subregion to integrate the received information before propagating it to adjacent areas (Freund and Katona, 2007; Pelkey et al., 2017; Nilssen et al., 2018). The local circuits of all hippocampal subregions are comprised of a glutamatergic principal neuron type and a wide range of largely GABAergic interneurons, which regulate neural activity mainly by feedforward and feedback inhibition (Sohal et al., 2009; Quattrocolo and Maccaferri, 2014; Schmidt-Hieber et al., 2017). Many interneurons can subserve both mechanisms, thus providing a functional link between afferent input patterns and resulting outputs (Bartos et al., 2010; Chamberland et al., 2010; Tyan et al., 2014). Neuron types exhibit distinct axonal and dendritic laminar distributions, defining specific connectivity patterns (Freund and Buzsáki, 1996; Klausberger and Somogyi, 2008; Booker and Vida, 2018). For example, CA1 oriens-lacunosum moleculare (O-LM) interneurons innervate only the apical tuft of pyramidal cells (PCs) in stratum lacunosum-moleculare (SLM) and receive inputs only in stratum oriens (SO) (McBain et al., 1994; Losonczy et al., 2002; Zemankovics et al., 2010).

Local interneuron circuits can generate recurrent activity patterns and transmit these rhythms onto principal cells for broader network propagation (Tukker et al., 2007; Gulyás et al., 2010; Quilichini et al., 2010). These oscillations underlie mechanisms of spatial navigation (Ekstrom et al., 2003; Colgin, 2016) and memory (Bauer et al., 2007; Jensen et al., 2007), implicating various interneuron types in different roles (Csicsvari et al., 2003; Szabó et al., 2010). Several extrinsic afferent pathways from the brainstem and forebrain nuclei also provide neuron type-selective modulation (Halasy and Somogyi, 1993; Witter et al., 2017; Kinnavane et al., 2018), powerfully shaping any subsequent output.

The online knowledge base www.Hippocampome.org identifies $>120$ neuron types throughout the hippocampal formation (Wheeler et al., 2015) based on axonal and dendritic morphology, intrinsic and synaptic electrophysiology (Komendantov et al., 2019; Venkadesh et al., 2019), and molecular expression (White et al., 2020). This public resource links each property to available experimental evidence annotated from the peer-reviewed literature (Hamilton et al., 2017).

Despite the wealth of knowledge regarding the rodent hippocampus, quantitative estimates of connection probabilities among specific neuron types are extremely sparse, accounting for only $5 \%$ of the estimated 3120 pairs of potentially connected neuron types ("potential connections"). Local circuits make up more than three-fourths of all potential connections in the hippocampal formation (Rees et al., 2016). Although much of these data can be derived in principle from electron microscopy, the painstaking amount of time, effort, and resources required for that approach has so far limited the connectivity quantification to a minor proportion of the circuit (Megías et al., 2001; Mishchenko et al., 2010; Schmidt et al., 2017).

Here we present a data-driven pipeline to estimate most local connection probabilities among www.Hippocampome.org neuron types. Using a custom image processing approach, we quantify the layer-specific distributions of axonal and dendritic lengths for $>200$ representative neuron morphology reconstructions from all subregions of the hippocampal formation. From these data, in conjunction with available volumes for each anatomic parcel and ultrastructural reports of synaptic interaction distances, we estimate the probability of spatial overlap between potential presynaptic axons and postsynaptic dendrites. Hence, we calculate the average number of synapses
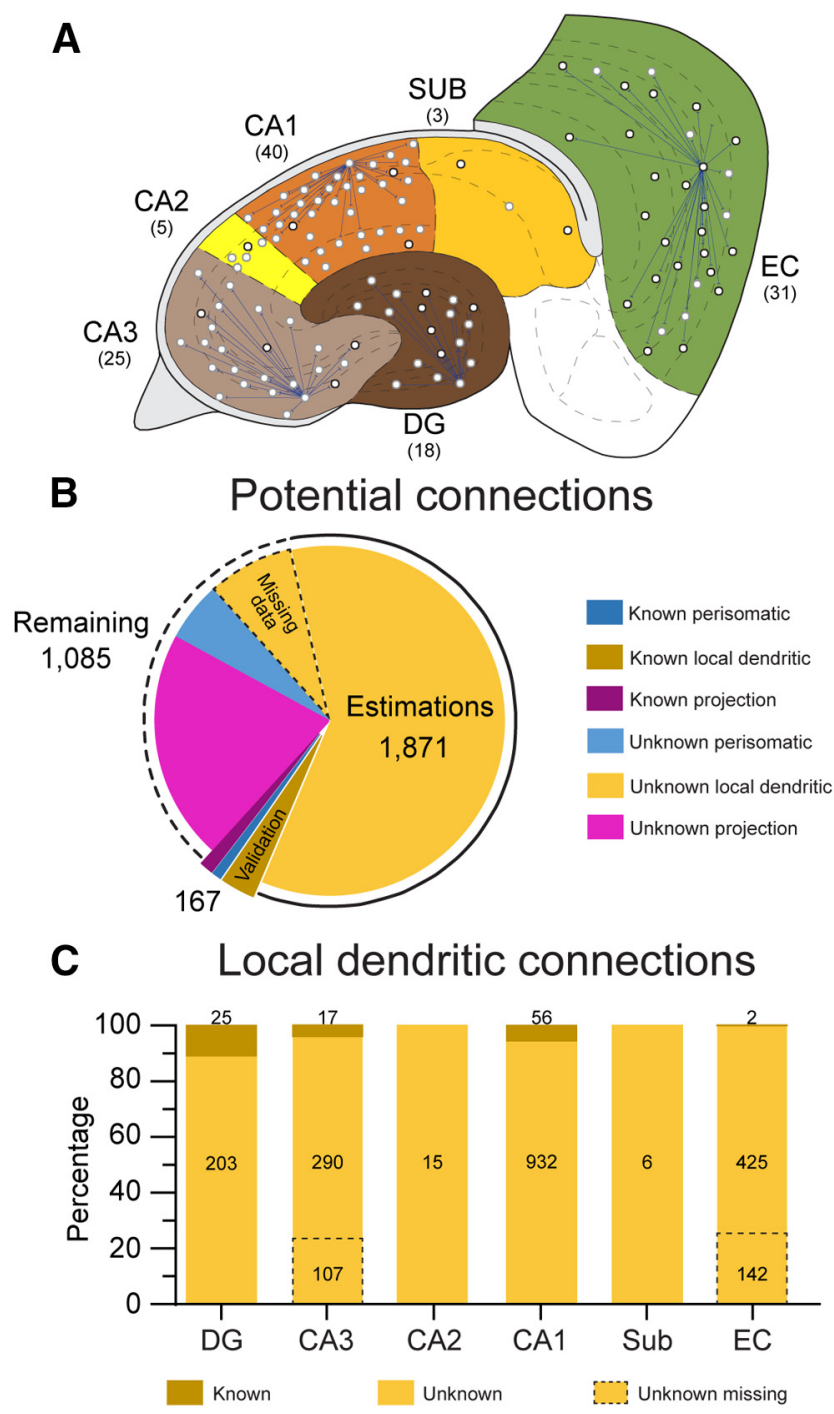

Figure 1. Hippocampal circuitry. $A$, Subregional delineation of the hippocampal formation. Circles represent neuron types. Numbers in parentheses indicate their counts. Blue arrows indicate the local outgoing connectivity of a representative neuron type for every major subregion: DG MOPP, CA3 bistratified, CA1 S0-S0, and EC LIII pyramidal. $\boldsymbol{B}$, The connection probability is unknown for most (2953) of the 3120 hippocampal potential synapses. Continuous line indicates the proportion of connection probabilities estimated by axonal-dendritic overlap. Dotted line indicates the connections excluded from analysis. C, Relative fractions and absolute numbers of local axonal-dendritic connections in each subregion, for which quantitative estimates were previously reported, were unknown and are estimated here, or remain unknown because of lack of morphologic reconstructions.

for almost 2000 pairs of neuron types (see Fig. 1) as well as their mean synaptic distances from the soma along the axonal and dendritic paths.

\section{Material and Methods}

Data sources. We analyzed 1-5 reconstructed morphologies per identified neuron type in www.Hippocampome.org (for representative examples, see Fig. 2A): 35 reconstructions for 18 neuron types in DG, 35 for 22 neuron types in CA3, 8 for 5 neuron types in CA2, 85 for 40 neuron types in CA1, 6 for 3 neuron types in Sub, and 56 for 27 neuron types in EC. Each two-dimensional reconstruction corresponds to a published neuronal tracing image in the peer-reviewed literature (detailed in Extended Data Figs. 2-1, 2-2, 2-3, 2-4, 2-5, 2-6; Gupta et al., 2012; Liu et al., 


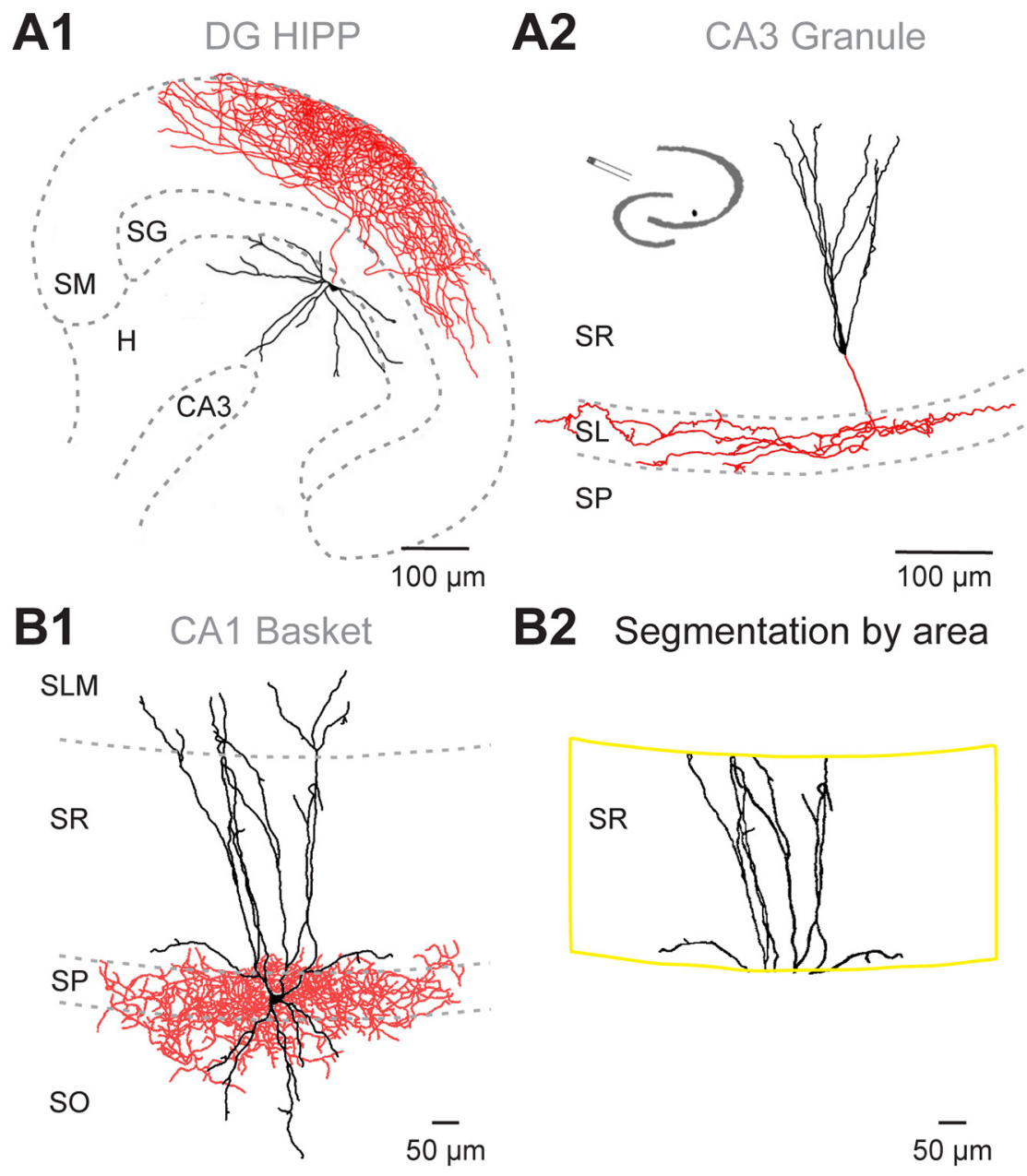

A3 LII Basket
Multipolar Interneuron

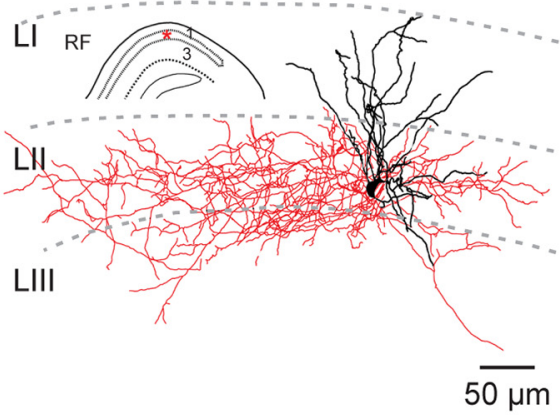

B3

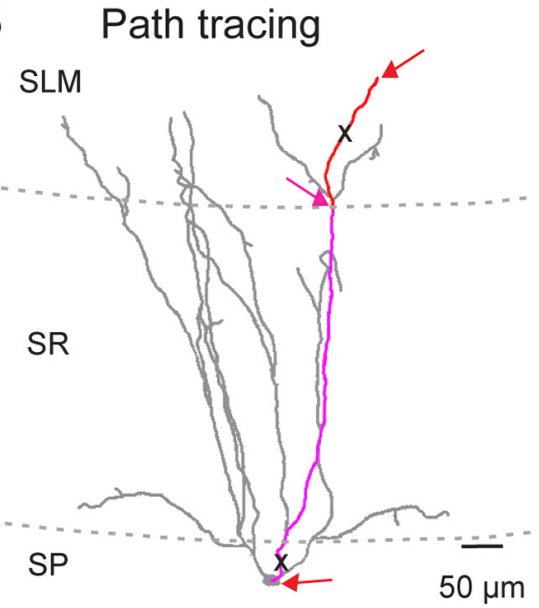

\section{C1 CA1 LMR-Projecting C2 CA1 Neurogliaform}

\section{C3}
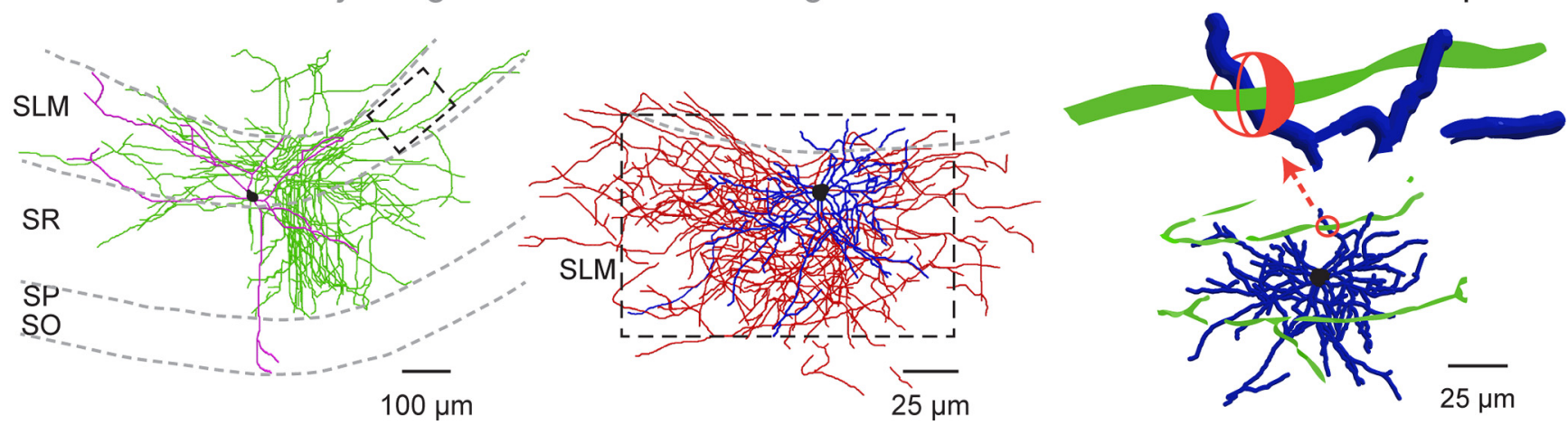

Figure 2. Morphologic reconstructions of hippocampal neuron types and their image processing. Details regarding the full dataset and sources are reported in Extended Data Figures 2-1-210. $\boldsymbol{A}$, Representative tracings of selected neuron types from different subregions of the hippocampal formation: black represents glutamatergic; gray represents GABAergic. A1, DG HIPP (Hosp et al., 2014); A2, CA3 Granule (Szabadics et al., 2010); A3, EC LII Basket Multipolar Interneuron (Tahvildari et al., 2012). B, Exemplary cases of image processing for pixel count and neurite path tracing. B1, CA1 Basket cell reconstruction (S. Y. Lee et al., 2011): red represents axons; black represents dendrites. B2, Extraction of the SR (yellow frame) dendrites from the original image. B3, Estimation of mean distance from the soma along the dendritic path. We traced and averaged up to five dendrites per parcel. C, Connection probability estimation. C1, CA1 LMRProjecting presynaptic interneuron. Reproduced from Klausberger et al. (2005). C2, CA1 Neurogliaform postsynaptic interneuron. Reproduced from Price et al. (2005). C3, Axonal-dendritic overlap in S0: green represents bistratified axons; blue represents 0 -LM dendrites. Orange sphere represents the zoomed-in volume of interaction (radius $=2 \mu \mathrm{m}) . \boldsymbol{A} \mathbf{1}, \boldsymbol{A 2}$ and $\mathbf{C 1} \mathbf{1 0 0} \mu \mathrm{m} ; \boldsymbol{A 3}$, B1-B3, 50 $\mu \mathrm{m}, \mathbf{C}$ and $\mathbf{C} 325 \mu \mathrm{m} . \boldsymbol{B}, \mathbf{C}$, Images have been modified from the originals to enhance colors.

2014; Han et al., 1993; Anderson et al., 2011; Spruston et al., 1997; Hájos et al., 2004, Hájos et al., 2013; Craig et al. 2015; Maccaferri et al., 1996; Kirson et al., 2000; Buhl et al., 1994; Pawelzik et al., 2002; Varga et al., 2014; Martínez et al. 1996; Lapray et al., 2012; Daw et al., 2009; Klausberger, 2009; Klausberger et al., 2004; Acsády et al., 1996a,b; Gulyás et al.,
1996; Tricoire et al., 2010; Fuentealba et al., 2008a,b; Karayannis et al., 2010; Fuentealba et al., 2010; Hájos et al., 1997; Tricoire et al., 2010; Martina et al., 2000), with sometimes multiple reconstructions coming from the same publication. We selected the reconstructions based on five inclusion criteria: (1) the neuron type was present in www.Hippocampome.org version 1.7 to 
obtain maximum coverage of the knowledge base; (2) the image contained a calibration scale bar and clear demarcations of relevant layer and subregional boundaries; (3) the traced dendritic and axonal distributions as well as soma location corresponded to the textual description in the source publication; (4) the reconstruction included both axons and dendrites, except for perisomatic-targeting neuron types (basket and axo-axonic cells), for which only dendrites were considered; and (5) axons and dendrites could be unambiguously discerned and ascribed to a single neuron type (for this reason, we excluded reconstructions from paired recordings).

It is important to note that the 225 used reconstructions come from 96 different publications encompassing a broad variety of experimental preparations (Extended Data Fig. 2-7; Hamam et al., 2000, 2002; Kispersky et al., 2012; Leão et al., 2012; Lee et al., 2010; Lübke et al., 1998; Szabó et al., 2014; Martónez et al., 1996; Gulyás et al., 1993; Canto et al., 2012a; Ferrante et al., 2016; Glickfield et al. 2006; Harris et al., 1999; Burgalossi et al., 2011; Hájos et al., 1998; Garden et al., 2008; Canto et al., 2012b; Ferraguti et al., 2005; Bell et al., 2013; McQuiston et al., 1999; Tahvildari et al. 2005; Middleton et al. 2008; Gloveli et al. 2001; Svoboda et al. 1999; Oliva et al., 2000; Soriano et al., 1993; Spruston et al. 2007), including differences in animal species, strain, age, and sex (both females and males were used), as well as histologic details, such as slice orientation, section thickness, recording technique, and labeling method. This heterogeneity of data sources requires adequate data normalization strategies, described in the next section, and extreme caution in interpreting the results (see Discussion).

Axonal and dendritic lengths. In order to extract parcel-specific neurite lengths, we isolated the axonal and dendritic reconstructions of each neuron type according to the different layers of each subregion (see Fig. $2 B$ ). Starting from the original unmodified image, we manually segregated the axons and dendrites within each anatomic parcel using the GNU Image Manipulation Program (GIMP 2.8; www.gimp.org), and separately saved the axonal and dendritic domains in distinct files for every layer and subregion. Next, we dissected each image into different channels for white (background) and nonwhite (neurites) pixels with a custom-made MATLAB algorithm (www. github.com/Hippocampome-Org/QuantifyNeurites), which returns the neurite pixel count. We carefully inspected each separate image channel to confirm visually that the algorithm isolated the appropriate signals. The length in pixels of the calibration scale bar was measured with the open-source program Plot Digitizer (www. plotdigitizer.sourceforge.net).

The conversion from pixel numbers to parcel-specific length requires three logical steps. The first accounts for the nonuniform tracing widths across images: often neuronal arbors (especially dendrites) are reconstructed with variable branch thickness ranging from single to multiple pixels. To solve this issue, we randomly selected three locations for every neuron image, parcel, and neurite domain, measured the branch width in pixels at each location, and averaged the three values. The second logical step requires calculating the pixel length in physical units, which is simply the nominal calibration scale-bar value (in microns) divided by the measured bar length in pixels. Consequently, the parcel-specific neurite length is obtained by multiplying the pixel count for that neurite in the given parcel by the physical pixel length and dividing the result by the average branch width in pixels. The final step corrects for the artifactual flattening of three-dimensional arbors into two-dimensional images by combining the parcel-specific lengths $l_{p}$ with the reported section thickness $t_{s}$ using Pythagoras' formula as follows:

$$
L_{\mathrm{p}}^{\mathrm{c}}=\sqrt{l_{\mathrm{p}}^{2}+t_{\mathrm{s}}^{2}}
$$

where $L_{p}^{c}$ represents the final corrected length.

The majority of the available reconstructions (78\%) were from rat, and most of those (56\% of the rat data) came from adult ( $\geq 1$-month-old) animals. For several neuron types, however, tracing data were only available for young adult (defined as 13-30 d old, consistent with www.Hippocampome.org) rats (34\%) or from mice $(21 \%)$. Normalizing all lengths to the adult rat setting requires two scaling factors: one for young to adult and another for mouse to rat. Seminal studies have measured the differences in arbor size between adult and juvenile rats in the hippocampus and elsewhere: Bannister and Larkman (1995) reported a length ratio of 1.10 for CA1 PCs, but this may be an underestimate because of nonuniform histologic processing, and pointed to parallel studies suggesting a ratio of 1.24 for the same neuron type (Ishizuka et al., 1995). Also investigating CA1 PCs, but solely focusing on the basal dendrites, Juárez et al. (2008) provided lengths corresponding to a ratio of 1.30 . The same authors also included data for principal cells in the PFC (adult/juvenile ratio of 1.14) as well as GABAergic neurons from the NAc (ratio of 1.20). Taking this evidence into consideration, we chose to correct the length measurements $\left(L_{p}^{c}\right)$ from young animals by the multiplicative factor of 1.20. In order to normalize mouse length values to rats, we used the cubic root of the parcel-specific volume scaling factor, which is described at the end of the next section (see below and compare Extended Data Fig. 2-8).

Average number of synapses per neuron pair. We calculate the average number of synapses per pair of presynaptic and postsynaptic neurons, $N_{s}$, from their parcel-specific axonal and dendritic lengths by separately estimating the numbers, $N_{s x}$ of axonal-dendritic overlaps in each parcel $x$ (Amirikian, 2005; DeFelipe, 2015). For any $x$, the value $N_{s x}$ can be derived as the product of three factors: the probability that presynaptic and postsynaptic elements occur within a given interaction distance $r$, the number of presynaptic elements (axonal boutons) in the given anatomic parcel, and the number of postsynaptic elements (dendritic spines or shafts) in the same parcel. The first factor is given by the ratio between the volume of the interaction sphere within which the two elements must be and the volume of the entire parcel, $V_{x}$. The second factor is given by the presynaptic axonal length in parcel $x, L_{a x}$, divided by the average distance between consecutive presynaptic boutons, $b_{d}$. The third factor is given by the postsynaptic dendritic length in $x, L_{d x}$, divided by the distance between postsynaptic elements, $s_{d}$ as follows

$$
N_{s x}=\frac{4 \pi r^{3}}{3 V_{x}} * \frac{L_{a x}}{b_{d}} * \frac{L_{d x}}{s_{d}}
$$

The total count of synapses per directed neuron pair, $N_{s}$, is just the sum of the numbers per parcel, $N_{s x}$ over all parcels.

The above calculation requires a series of realistic assumptions regarding the needed parameters. We obtained the average dendritic distance between postsynaptic elements, $s_{d}$, and axonal distance between presynaptic elements, $b_{d}$, from available ultrastructural measurements in the rodent hippocampus (1.09 and $6.2 \mu \mathrm{m}$, respectively: Extended Data Figs. 2-9, 2-10; Armstrong et al., 2011; Vida, 2010; Sik et al., 1994; Gould et al., 1990; Moser et al., 1994; Pierce et al., 2011; Papa and Segal 
1996; Harris and Stevens 1989; Sunanda and Rao, 1995). Moreover, we set the interaction radius $r$ (see Fig. $2 C$ ) to $2 \mu \mathrm{m}$, corresponding to a sphere with $4 \mu \mathrm{m}$ diameter, according to the sum of two components: a $2.5 \mu \mathrm{m}$ assessment for bouton size and synaptic spillover (Coddington et al., 2013) plus a $1.5 \mu \mathrm{m}$ estimate similarly ascribed to dendritic spine reach (Papa and Segal, 1996) and aspiny dendrite thickness (Stepanyants et al., 2004; Mishchenko et al., 2010). For lack of more specific information, these parametric estimates were applied equally to all pairings of neuron types evaluated.

Stereological investigations offer $>$ suitable estimates for a subset of the required anatomic parcel volumes, $V_{x}$, for the adult rat, namely, all layers of DG, CA3, and CA1 (Extended Data Fig. 2-8). Overall volumes (though not laminar subdivisions) are also available for CA2 and for the whole hippocampal-subicular complex, but data are missing altogether for the Sub proper and all layers of the EC (Kamsu et al., 2013). To fill in the required missing values, we leverage the Allen Reference Atlas, which provides volumes for each hippocampal parcel in the adult mouse brain (Erö et al., 2018). Specifically, we calculate a rat/mouse ratio for the overall CA2 volume and apply that to each CA2 layer; we then compute by subtraction the rat Sub volume and use it to calculate a rat/mouse Sub ratio to derive rat estimates for each subicular layer. Last, we use the rat/mouse volumetric ratio computed over the entire hippocampal formation to estimate the volumes for all entorhinal layers (Extended Data Fig. 2-8; Coleman et al., 1987; Rapp et al., 1999; Sousa et al., 1999; Wolf et al., 2002; Lee et al., 2009; Ropireddy et al., 2012).

Number of contacts per connected pair, convex hulls, and connection probabilities. The number $N_{s}$, defined above, can be also construed as the expected number of contacts (in parcel $x$ ) per connected neuron pair, $N_{c x}$, multiplied by the connection probability, $p_{x}$, between the presynaptic and postsynaptic neurons in parcel $x$. The first of these values, $N_{c x}$, can be derived using a similar logic as harnessed in the formulation of $N_{x}$, except that the relative position of the presynaptic and postsynaptic elements is now constrained by the extant contact between their respective neurons. In other words, the space available to form synapses between connected neurons is not the entire volume of parcel $x$, but only the volume of intersection, or overlap, $V_{o}$, between the presynaptic axons and postsynaptic dendrites in that parcel. Thus, if a given pair of neurons forms at least a single synaptic contact, the expected number of additional contacts for that pair is as follows:

$$
N_{\mathrm{cx}}=\frac{4 \pi r^{3}}{3 V_{\mathrm{o}}} * \frac{L_{a x}}{b_{d}} * \frac{L_{d x}}{s_{d}}
$$

where the volumetric ratio between the sphere defined by the radius of interaction $r$ and $V_{o}$ represents the chance of encounter for any given pair of axonal boutons and dendritic spines or shafts, and $L_{a x} / b_{d}$ and $L_{d x} / s_{d}$ correspond, respectively, to the number of axonal boutons and dendritic spines or shafts in parcel $x$. The volume of intersection, $V_{o}$, is given by the following:

$$
V_{o}=f_{o}\left(V_{d x}+V_{a x}\right)
$$

where $V_{d x}$ and $V_{a x}$ are the subvolumes of parcel $x$ invaded by the postsynaptic dendrite and presynaptic axon, respectively, and $f_{o}$ is the overlap factor, which varies from $\frac{1}{2}$ at complete overlap to zero at a single point of synaptic contact. On average, the volume of overlap in parcel $x$ is therefore given by the following:

$$
V_{o}=\frac{1}{4}\left(V_{d x}+V_{a x}\right)
$$

To measure $V_{d x}$ and $V_{a x}$, we extract the convex hull areas in parcel $x$ from the isolated axonal and dendritic images for each reconstruction, using the Shape Analysis plug-in (Wagner and Lipinski, 2013) of the open-source software Fiji. Then we convert the area measurements from pixel units to $\mu \mathrm{m}^{2}$ and multiply the resultant values by the reported slice thicknesses.

The overall number of contacts per connected pair is the sum of the contacts in each parcel augmented by one, reflecting the initial assumption that the neuron pair is connected as follows:

$$
N_{c}=1+\sum_{x} N_{c x}
$$

where the symbol $\Sigma_{x}$ represents the sum over all parcels.

The connection probability for a pair of neuron types in parcel $x$ is obtained by dividing the average number of synapses per neuron pair by the number of contacts per connected pair in the same parcel as follows:

$$
p_{x}=\frac{N_{x}}{N_{c x}}=\frac{V_{o}}{V_{x}} .
$$

The overall probability of connection for a pair of presynaptic and postsynaptic neurons in any parcel is given by the sum of inclusive events as follows:

$$
p=1-\Pi_{\mathrm{x}}\left(1-\boldsymbol{p}_{\mathrm{x}}\right),
$$

where the symbol $\Pi_{x}$ represents the product over all parcels.

Axonal and dendritic path distances. In order to estimate synaptic path distance from the soma along the axons and dendrites, we used the Simple Neurite Tracer plug-in (Longair et al., 2011) of Fiji. Starting from the soma, we traced up to 5 distinct dendritic and axonal paths for each neuron and parcel. We then converted the length measurements from default pixel units to microns using the pixel length extracted from the calibration scale bar as described above. For a neurite ending in a parcel, the ending point constitutes the maximum path distance for that parcel. For neurites crossing into a subsequent parcel, the crossing point corresponds to the maximum path distance. Similarly, for neurites crossing from a previous parcel, the crossing point constitutes the minimum path distance. For somatic parcels, the minimum distance is zero. In all cases, the average path distance for a neurite in a parcel was calculated as the average between minimum and maximum. The mean and SD of these averages were computed over different paths.

Experimental design and statistical analysis. We calculated the connection probabilities, number of contacts per connected pairs, and somatic distances along the presynaptic axon and postsynaptic dendrite from the neurite lengths measured for every neuron type in each subregion and layer, as described above. In order to validate the axonal and dendritic length measurements, we used Pearson's correlation analysis for comparing our results with independent reports and, whenever available, with author-reported values for individual neuron reconstructions. Similarly, we used Pearson's correlation analysis to compare our estimated number of 
Table 1. Total length estimations of neurites compared with previous reports ${ }^{\mathrm{a}}$

\begin{tabular}{|c|c|c|c|c|}
\hline Area & Neuron type & Reported length & Estimated length & Reference \\
\hline \multirow[t]{13}{*}{ DG } & \multirow[t]{3}{*}{ Granule } & D: $2793 \pm 74 \mu \mathrm{m}$ & \multirow[t]{3}{*}{ D: $3538.9 \pm 328.4 \mu \mathrm{m}$} & Claiborne et al., 1986 \\
\hline & & D: $3337 \pm 88 \mu \mathrm{m}$ & & Buckmaster et al., 1992 \\
\hline & & D: $3221 \pm 78 \mu \mathrm{m}$ & & Patton and McNaughton, 1995 \\
\hline & Mossy & D: $5392 \pm 313 \mu \mathrm{m}$ & D: $4792.9 \pm 395.9 \mu \mathrm{m}$ & Kowalski et al., 2010 \\
\hline & Basket & D: $9800 \mu \mathrm{m}$ & D: $6583.4 \pm 4277.1 \mu \mathrm{m}$ & Bartos et al., 2001, 2002 \\
\hline & \multirow[t]{2}{*}{ MOCAP } & $\mathrm{D}: 1108 \mu \mathrm{m}$ & $\mathrm{D}: 1258.3 \mu \mathrm{m}$ & \multirow[t]{2}{*}{ Markwardt et al., 2011} \\
\hline & & $\mathrm{A}: 15,750 \mu \mathrm{m}$ & A: $14,438.3 \mu \mathrm{m}$ & \\
\hline & HICAP & A: $9700 \pm 200 \mu \mathrm{m}$ & A: $7745.2 \pm 642.0 \mu \mathrm{m}$ & Mott et al., 1997 \\
\hline & \multirow[t]{3}{*}{ HIPP } & D: $2500-3200 \mu \mathrm{m}$ & $\mathrm{D}: 3839.3 \pm 7.3 \mu \mathrm{m}$ & \multirow[t]{2}{*}{ Yuan et al., 2017} \\
\hline & & A: $22,500-26,800 \mu \mathrm{m}$ & A: $23,708.7 \pm 1683.5 \mu \mathrm{m}$ & \\
\hline & & & $\mathrm{A}: 25,780 \mu \mathrm{m}$ & Sik et al., 1997 \\
\hline & \multirow[t]{2}{*}{ Total molecular layer } & D: $2500-3200 \mu \mathrm{m}$ & D: $3074.3 \mu \mathrm{m}$ & \multirow[t]{2}{*}{ Mott et al., 1997} \\
\hline & & $\mathrm{A}: 22,500-26,800 \mu \mathrm{m}$ & $\mathrm{A}: 21,136.4 \mu \mathrm{m}$ & \\
\hline \multirow[t]{3}{*}{ CA3 } & Pyramidal & D: $12,481 \pm 2998.9 \mu \mathrm{m}$ & D: $14,624.6 \pm 4604.0 \mu \mathrm{m}$ & Ishizuka et al., 1995 \\
\hline & Mossy fiber-associated & A: $20.3-28.6 \mathrm{~mm}$ & $\mathrm{~A}: 21,750.9 \pm 1714.2 \mu \mathrm{m}$ & Vida and Frotscher, 2000 \\
\hline & Trilaminar & A: $99,770 \mu \mathrm{m}$ & A: $67,180.4 \pm 31,195.4 \mu \mathrm{m}$ & Sik et al., 1997 \\
\hline \multirow[t]{2}{*}{ CA2 } & Pyramidal & D: $15,405.8 \pm 949.7 \mu \mathrm{m}$ & $\mathrm{D}: 11,111.0 \pm 4237.0 \mu \mathrm{m}$ & Ishizuka et al., 1995 \\
\hline & SP-SR & D: $4200 \mu \mathrm{m}$ & D: $4152.9 \mu \mathrm{m}$ & Mercer et al., 2012 \\
\hline \multirow[t]{3}{*}{ CA1 } & Pyramidal & $\mathrm{D}: 11,915 \pm 1030.0 \mu \mathrm{m}$ & D: $10,957.4 \pm 1669.4 \mu \mathrm{m}$ & Bannister and Larkman, 1995 \\
\hline & & D: $13,424.2 \pm 1060.9 \mu \mathrm{m}$ & & Ishizuka et al., 1995 \\
\hline & Basket $\mathrm{CCK}^{+}$ & D: $6338 \mu \mathrm{m}$ & D: $7372.6 \pm 598.4 \mu \mathrm{m}$ & Mátyás et al., 2004 \\
\hline
\end{tabular}

${ }^{a}$ See also Extended Data Table 1-1; Buckmaster, 2012.

contacts per connected pair with values previously reported for a subset of CA1 neuron types (Bezaire and Soltesz, 2013).

Once we pooled several neurite measurements to determine the means and SDs of the neurite lengths and convex hull volumes, we used SE-propagation formulas for sums and differences as follows:

$$
\begin{gathered}
C=x+y-z \\
\Delta C=\sqrt{(\Delta x)^{2}+(\Delta y)^{2}+(\Delta z)^{2}},
\end{gathered}
$$

and products and quotients as follows:

$$
\begin{gathered}
C=\frac{x \cdot y}{z} \\
\Delta C=|C| \sqrt{\left(\frac{\Delta x}{x}\right)^{2}+\left(\frac{\Delta y}{y}\right)^{2}+\left(\frac{\Delta z}{z}\right)^{2}},
\end{gathered}
$$

to calculate the final uncertainties for the average number of synapses per neuron pair, for the number of contacts per connected pair, and for the connection probabilities. Factors, such as the volume of interaction and the parcel volumes, were considered constants. In instances where there was only a single example of a presynaptic neuron type and only a single example of a postsynaptic neuron type, we assigned a value of "N/A" to the associated uncertainties.

Resource sharing. All results and underlying experimental data are freely available through the www.Hippocampome. org web portal. Specifically, the following values are available at www.hippocampome.org/php/synapse_probabilities.php: means and SDs of dendritic and axonal lengths for all neuron types and parcels; means, SDs, minima, and maxima of the synaptic distances from the soma along the axonal and dendritic paths, for all potentially connected neuron-type pairs and parcels; and means and SDs for the connection probabilities, average numbers of synapses per neuron pair, and numbers of contacts per connected pair, for all pairs of potentially connected neuron types. Each set of values is linked to the morphologic reconstruction images from which they were extracted. Additionally, we also provide an online tool at www.hippocampome.org/php/connprob.php to recalculate the connection probability and number of contacts per connected pair for any pair of neuron types on altering the assumptions regarding interbouton and interspine distances as well as interaction radius.

\section{Results}

\section{Potential connectivity}

The 122 neuron types identified by www.Hippocampome.org volume 1.7, across the six subregions of the rodent hippocampal formation (Fig. 1A), give rise to 3120 potential synaptic connections based on spatial colocation of presynaptic and postsynaptic elements (Moradi and Ascoli, 2020). Over 71\% (2220) of these connections arise from dendritic-targeting axons in local circuits, with the rest consisting mainly of projections between different subregions (23\%) and a minority of perisomatic contacts from basket and axo-axonic cells (6\%). Only for 167 potential connections (5\%) has the synaptic interaction been experimentally established (Rees et al., 2016): the remaining, including 2120 local dendritic connections, so far lack any quantitative assessment of synaptic connectivity (Fig. $1 B$ ). Our approach allows for estimating the synaptic connectivity parameters (connection probability and number of contacts per connected pair) of 1970 potential synapses: 1870 for which no data were previously reported and 100 for which at least partial data exists in the literature. The last 250 local dendritic connections cannot be estimated because of the unavailability of morphologic reconstructions for the presynaptic or postsynaptic neurons. Together, the present work fills nearly two-thirds of the missing data in the hippocampal formation, increasing the available knowledge $>11$-fold and leaving only a minority $(<35 \%)$ of the potential synaptic connections unknown. Notably, prior information was mainly limited to DG and area CA1, whereas residually absent estimates are restricted to EC and CA3 (Fig. 1C).

\section{Axonal and dendritic length validation}

We validated our pixel-count neurite-length-estimation pipeline (Fig. 2) with two independent approaches. First, we compared 
A
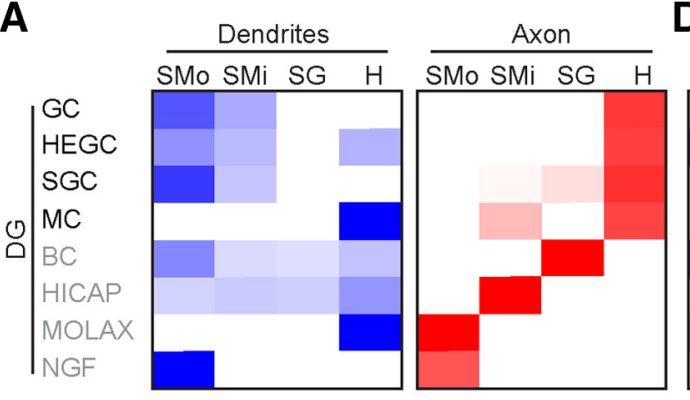

D Dendrites

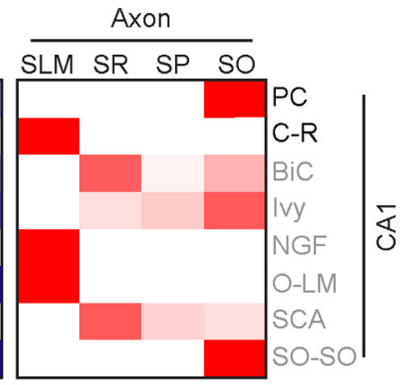

B

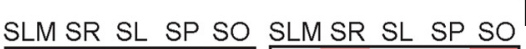

E SM

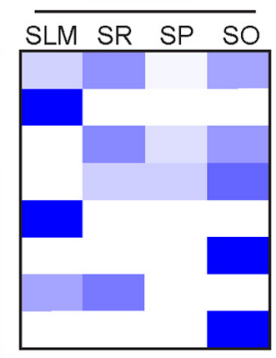

集

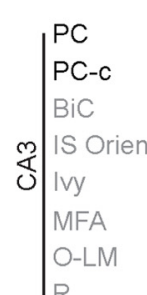

SLM SR SL SP SO

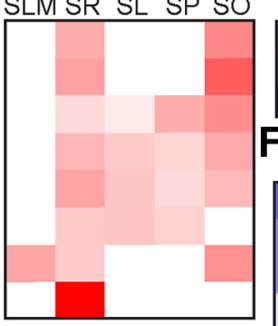

C

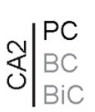

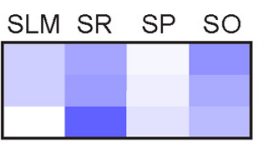

SLM SR SP SO
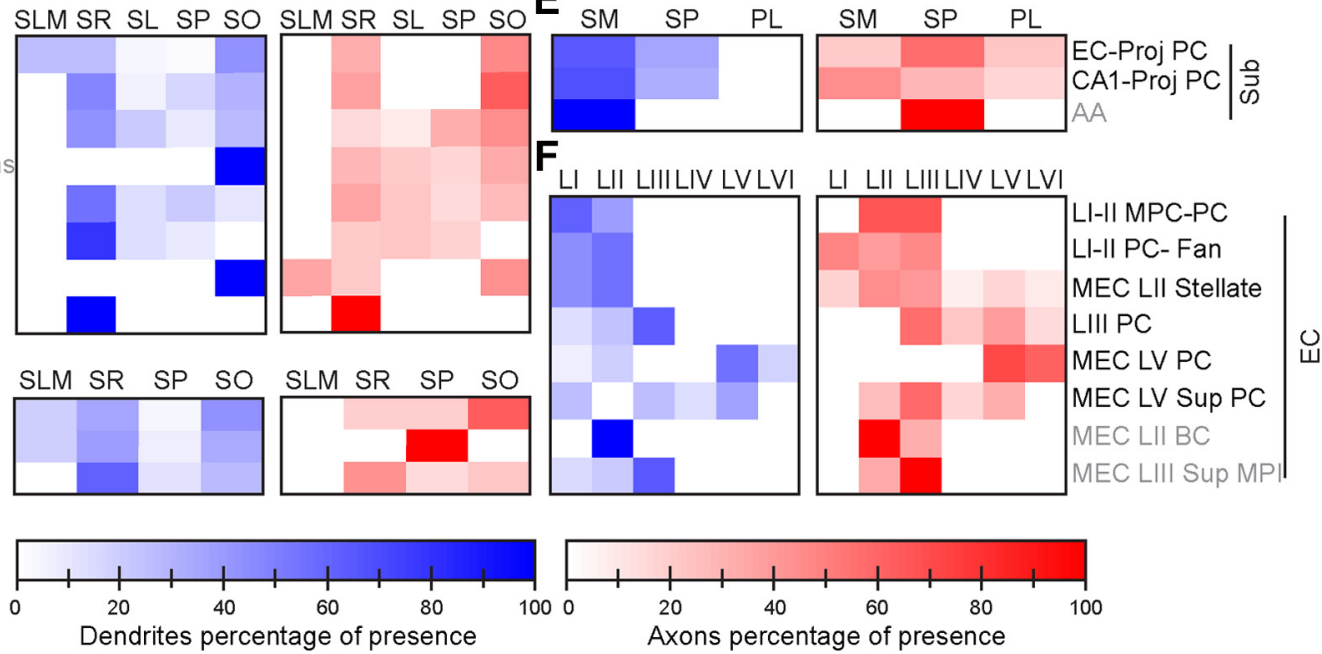

Figure 3. Relative laminar distributions of dendritic and axonal patterns across subregions (see Extended Data Figures 3-1-3-6 for absolute means and SDs). Heatmap distributions of dendrites (blue) and axons (red) for representative neuron types in DG $(\boldsymbol{A}), \mathrm{CA} 3(\boldsymbol{B}), \mathrm{CA} 2(\boldsymbol{C}), \mathrm{CA} 1(\boldsymbol{D})$, Sub $(\boldsymbol{E})$, and EC (F) ( $n=8$ for DG, CA3, CA1, and EC; $n=3$ for CA2 and Sub). Each row corresponds to the labeled neuron type (black represents glutamatergic; gray represents GABAergic), and each column represents a different subregion's layer. HEGC, Hilar Ectopic Granule; SGC, Semilunar GC; MC, Mossy cell; BC, Basket cell; HICAP, Hilar Commissural Associational Pathway-related cell; MOLAX, Total Molecular Layer cell with only MOlecular Layer AXons; NGFC, Neurogliaform cell; PCC, CA3c PC; BiC, Bistratified cell; IS Oriens, Interneuron-Specific Oriens; MFA, Mossy Fiber-Associated cell; R, Radiatum cell; C-R, Cajal-Retzius cell; SCA, Schaffer Collateral-Associated cell; SO-SO, Stratum OriensOriens cell; EC-Proj-PC, Entorhinal Cortex Projection PC; CA1-Proj PC, CA1 projection PC; AA, Axo-Axonic cell; LI-II MPC-PC, LI-II Multipolar-PC; LI-II PC-fan, LI-II Pyramidal-Fan cell; MEC LII Stellate, MEC LII Stellate cell; MEC LV Sup PC, MEC LV Superficial PC; MEC LII BC, MEC LII Basket cell; MEC LIII Sup MPI, MEC LIII Superficial Multipolar Interneuron cell.

our estimations with independent reports of axonal and dendritic length for the same neuron types (Table 1). The results show a tight correspondence between our estimations and the original measurements (ratio $=0.96 \pm 0.19$; Pearson's correlation $=0.99$, $p<0.001$ ). Second, we identified a subset of reconstructions for which the authors also directly reported neurite lengths (Extended Data Table 1-1), again demonstrating a tight alignment (ratio= $0.89 \pm 0.12$; Pearson's correlation $=0.90, p<0.005$ ). While these data are largely sourced from slice preparations, we include for completeness a comparison with in vivo reconstructions, when available (Extended Data Table 1-2; Scorcioni \& Ascoli, 2005). As expected, the traceable extent of axons intracellularly labeled in vivo is substantially longer and more variable because of factors, such as the duration of current injections (Li et al., 1993).

\section{Laminar distributions of axons and dendrites}

The distribution of local axonal and dendritic lengths across layers of the hippocampal formation varies by neuron type and subregion. Here we report the relative proportions (Fig. 3) as well as the means and SDs (Extended Data Figs. 3-1, 3-2, 3$3,3-4,3-5,3-6)$ for a representative subset of neuron types in each subregion. The comprehensive data for all neuron types are available at www.hippocampome.org/php/synapse_ probabilities.php. For neuron types whose axon invades different subregions, we only account for the local collaterals in this analysis. For example, only $78.3 \pm 8.3 \%$ of the DG Granule cell (GC) axons remain in the hilus, while the remaining $21.6 \pm 9.64 \%$ (not shown) cross over into CA3 stratum lucidum (SL) and stratum pyramidale (SP). DG interneurons regulate GC activity by innervating specific parcels (Fig. 3A; Extended Data Fig. 3-1). For instance, DG basket cells innervate stratum granulosum (SG), whereas HICAP neurons extend their axons into the inner onethird of stratum moleculare. Both interneuron types spread their dendrites across all four DG layers, although nearly half of the Basket cell dendrites $(>48 \%)$ are found in the outer two-thirds of stratum moleculare (SMo), while the HICAP distribution is more uniform (27\% in SMo, $41 \%$ in hilus, and 32\% between SG and inner one-third of stratum moleculare). Other interneurons, such as HIPP and MOPP, restrict their axon terminals within SMo and are differentiated by their dendrite localizations: HIPP in hilus and MOPP in SMo.

For the CA3 local circuit, we illustrate 8 of 22 neuron types (Fig. 3B; Extended Data Fig. 3-2), with the remaining data reported online. The CA3 principal cells are the PC, whose local axons form recurrent collaterals in stratum radiatum (SR) and SO and dendrites invade in different proportions all layers: SLM, SR, SL, SP, and SO. Our estimations confirm previous reports indicating that basal dendrites account for $\sim 42 \%-45 \%$ of the whole dendritic tree (Ishizuka et al., 1990). Whereas both CA3 Ivy and Bistratified cells have axons and dendrites extending 
from SR to SO, the present analysis reveals that bistratified cells are 3- to 4-fold longer than ivy in both axonal (55.6 $\mathrm{mm}$ vs 18.4 $\mathrm{mm})$ and dendritic trees $(14.3 \mathrm{~mm}$ vs $3.3 \mathrm{~mm})$. Other CA3 interneurons (e.g., O-LM or Interneuron-Specific Oriens and Radiatum cells) restrict their dendrites to $\mathrm{SO}$, while $\mathrm{CA} 3$ radiatum cells confine into a single layer both their axons and dendrites.

In area CA2 (Fig. 3C; Extended Data Fig. 3-3), PCs also distribute their dendrites across all layers but concentrate their axons in SO (63.6 $\pm 24.0 \%)$, with smaller proportions in SR and SP, again corroborating earlier reports (Ishizuka et al., 1995). CA2 Bistratified neurons display quantitatively similar axonal and dendritic patterns from SR to SO, aligned with the arbor distributions of homologous cell types in different hippocampal subregions (Mercer et al., 2007).

www.Hippocampome.org volume 1.7 identifies 37 distinct interneuron types in subregion CA1 (compare Somogyi and Klausberger, 2005), 8 of which were further investigated by Bezaire and Soltesz (2013). CA1 PCs have dendrites spanning all layers in proportions comparable to previous reports (Bannister and Larkman, 1995; Ishizuka et al., 1995) but axons restricted to SO (Fig. 3D; Extended Data Fig. 3-4). Axo-axonic, fast-spiking Basket, and Basket $\mathrm{CCK}^{+}\left(\mathrm{BC} \mathrm{CCK}^{+}\right)$types innervate only SP, directly modulating CA1 PC somatic activity, similarly to previous reports (Fuchs et al., 2007). Our analysis shows that among the dendritic-targeting interneurons, Bistratified and Schaffer Collateral-associated Axons mainly innervate SR, whereas CA1 Ivy cells show a strong preference $(\sim 68 \%)$ for SO. Other neuron types exclusively target SLM (e.g., Neurogliaform and O-LM cells).

www.Hippocampome.org identifies three neuron types in the Sub (Fig. 3E; Extended Data Fig. 3-5). The EC-Projecting and CA1-Projecting PCs show qualitatively similar, but quantitatively distinct, dendritic and local axonal distributions, whereas subicular Axo-axonic cells have dendrites restricted to SM and axons to SP. Interestingly, the local subicular circuit includes axons in the polymorphic layer, despite the dearth of identified postsynaptic elements in www.Hippocampome.org volume 1.7. This underscores the prospect of discovering new neuron types in this subregion to receive the transmitted signals (Kinnavane et al., 2018) (see Discussion).

The EC is traditionally divided into lateral and medial (MEC) components, respectively, implicated by electrophysiological evidence in objects representations and spatial tasks and underlying distinguishable connectivity patterns (Masurkar et al., 2017). Despite this functional and architectural partition, several neuron types are common to both areas (Canto et al., 2008), such as LI-II Multipolar-Pyramidal, LI-II Pyramidal-Fan, LIII Pyramidal, each with their own quantitatively distinct axonal-dendritic distributions (Fig. 3E; Extended Data Fig. 3-6). Stellate cells are the most numerous neuron type in MEC, with dendrites equally distributed across layers I and II and axons spread across all six layers, according to our analysis. In addition, our results indicate that two identified interneuron types have axonal innervations restricted to the superficial layers of MEC: LII Basket, LIII Superficial Multipolar Interneuron; however, the former preferentially target LII ( $>75 \%)$, whereas the latter target LIII (>83\%). We report further quantitative data for all additional neuron types at www.hippocampome.org/php/synapse_probabilities.php.

\section{Connection probability}

Based on the dendritic and axonal length distributions, we estimated the connection probability $p$ (Eq. 8), for each directional pair of neuron types in the local circuit (Fig. 4). This probability can be interpreted as the average fraction of neurons of the postsynaptic type contacted by a given neuron of the presynaptic type or, equivalently, the average fraction of neurons of the presynaptic type contacting a given neuron of the postsynaptic type. Figure 4 illustrates the complete set of probabilities by presynaptic sources and postsynaptic targets for the main hippocampal subregions. Here we summarize the mean values and coefficients of variation $(\mathrm{CV})$ for each "connection category": excitatory to excitatory (E-E), inhibitory to excitatory (I-E), excitatory to inhibitory (E-I), and inhibitory to inhibitory (I-I). Specifically, within each subregion, we average the individual connection probabilities for all pairs of neuron types corresponding to each connection category; for example, the E-E category includes all pairs of excitatory presynaptic neuron type and excitatory postsynaptic neuron type as long as the presynaptic axons share at least one parcel with the postsynaptic dendrites (defining a potential connection) and unless that connection has not been refuted experimentally (Rees et al., 2016).

The local DG circuit (Fig. 4A), which includes five different glutamatergic types, including GCs (that do not have potential connections with each other), exhibits a greater connection probability for E-E pairs $(0.66 \pm 0.10 \%$, CV range $=0.18-1.60, n=21$ pairs of neuron types) than for I-E pairs $(0.59 \pm 0.08 \%, \mathrm{CV}$ range $=0.15-2.45, n=44)$, with intermediate values for E-I $(0.61 \pm 0.08 \%$, CV range $0.11-2.09$, $n=53)$ and I-I $(0.59 \pm 0.06 \%, \mathrm{CV}$ range $0.20-4.04, n=110)$. In contrast, connectivity analysis in CA3 (Fig. 4B) reveals a higher probability from inhibitory cells (I-E: $0.81 \pm 0.11 \%$, CV range $=0.04-4.08, n=38$; I-I: $0.59 \pm 0.04 \%$, CV range $=0.07-$ $3.54, n=213$ ) than from the three types of excitatory cells (E-E: $0.40 \pm 0.09 \%, \mathrm{CV}$ range $=0.04-2.94, n=8$; E-I: $0.35 \pm 0.05 \%, \mathrm{CV}$ range $=0.04-2.98, n=48)$. The probability of CA3 PCs to CA3 PCs, alone, is $1.0 \pm 0.41 \%$ (well matching the $0.9 \%$ experimental value measured by Guzman et al., 2016). This relative trend holds true for CA2 (not shown in Fig. 4 but included in the online data at www.Hippocampome.org) and CA1, too, although with dramatic and opposite differences in absolute values: nearly an order of magnitude greater in CA2 (I-I: $5.5 \pm 1.5 \%, \mathrm{CV}$ range $=0.36-0.80, n=8$; I-E: $5.3 \pm 3.0 \%, \mathrm{CV}$ range $=0.43-0.70$, $n=2$; E-I: $3.6 \pm 2.1 \%$, CV range $=0.80-1.40, n=4$; and $\mathrm{E}-\mathrm{E}$ : $3.1 \pm 3.3 \%, \mathrm{CV}=1.04, n=1$ ) and smaller in CA1 (I-I: $0.32 \pm$ $0.02 \%, \mathrm{CV}$ range $=0.02-4.99, n=852$; I-E: $0.38 \pm 0.09 \%, \mathrm{CV}$ range $=0.02-4.01, n=62$; E-I: $0.09 \pm 0.04 \%$, CV range $=0.68-$ $6.23, n=69$; and E-E: $0.07 \pm 0.13 \%, \mathrm{CV}$ range $=1.19-5.30, n=5$ ). Because of the small number of neuron types discovered in the Sub to date, there are no characterized local axonal-dendritic inhibitory synaptic connections, and the data are very sparse for the excitatory connections (E-E: $1.4 \pm 0.2 \%$, CV range $=0.21$ $0.65, n=4$; E-I: $0.28 \pm 0.09 \%$, CV range $=0.35-1.06, n=2)$. The EC displays a pattern of synaptic-connection probabilities with greatest proportions for I-E $(0.38 \pm 0.22 \%$, CV range $=0.23-4.54$, $n=32)$ and smallest for E-I $(0.25 \pm 0.19 \%, C V$ range $=0.32-5.72$, $n=61)$, with intermediate values for I-I $(0.30 \pm 0.26 \%$, CV range $=0.73-4.54, n=10)$ and $\mathrm{E}-\mathrm{E}(0.33 \pm 0.07 \%, \mathrm{CV}$ range $=$ $0.22-5.72, n=323)$, the latter of which excludes the refuted MEC LII Stellate to MEC LII Stellate connections (Dhillon and Jones, 2000; Couey et al., 2013; Kelsch et al., 2014).

Across all local circuits of the hippocampal formation, this analysis reveals considerably variable, but overall sparse, axonaldendritic connection probabilities (mean \pm SD: $0.55 \pm 0.79 \%$ ) exhibiting a long tail distribution (Fig. $4 E$ ), well described by a log-normal function (Fig. $4 F$ ), with a range spanning four orders of magnitude (0.0084\%-9.9\%) and a median of $0.33 \%$.

The (very sparse) estimates available in the experimental literature (Extended Data Fig. 4-1) generally fall within the 
A

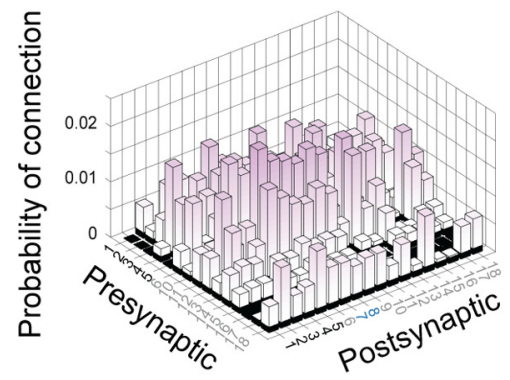

B

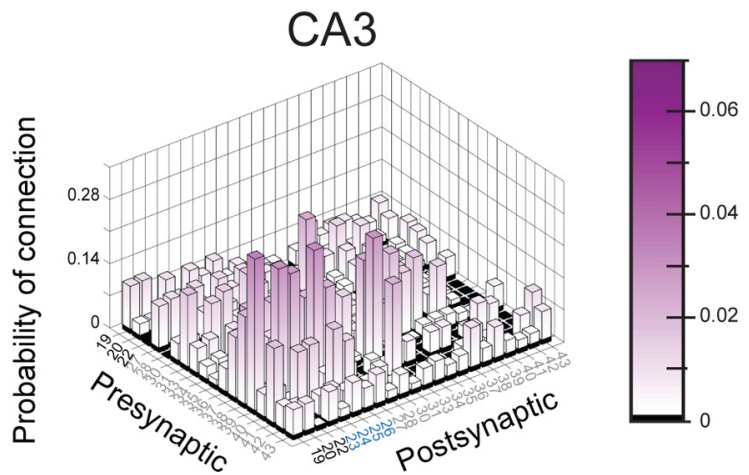

C

CA1

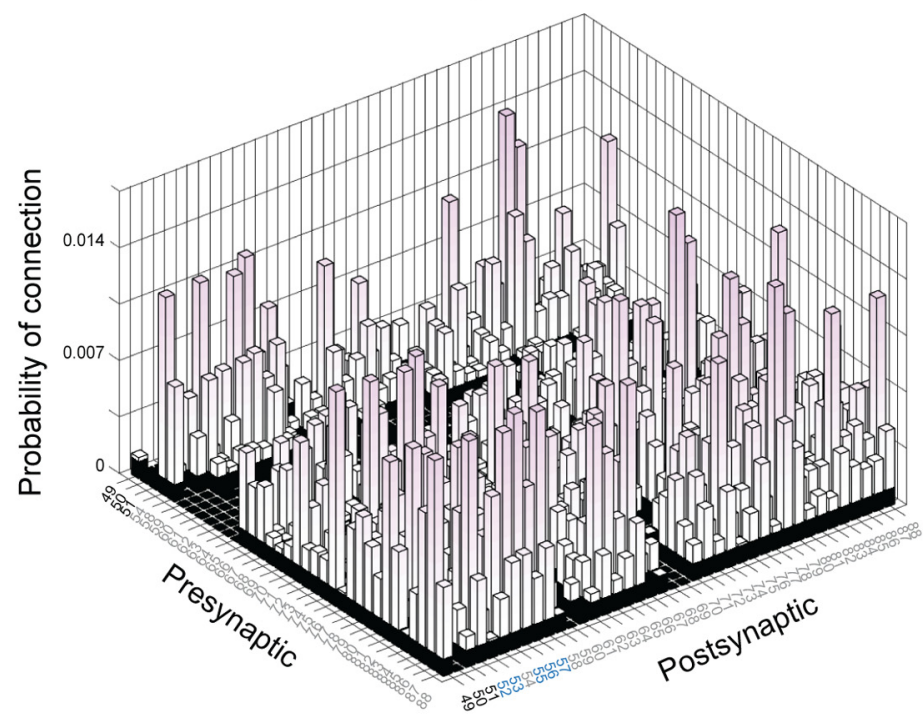

D

\section{Entorhinal Cortex}

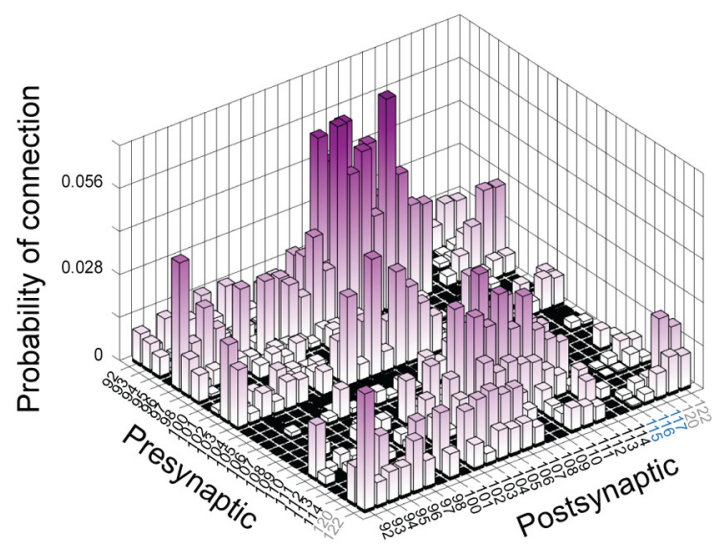

E

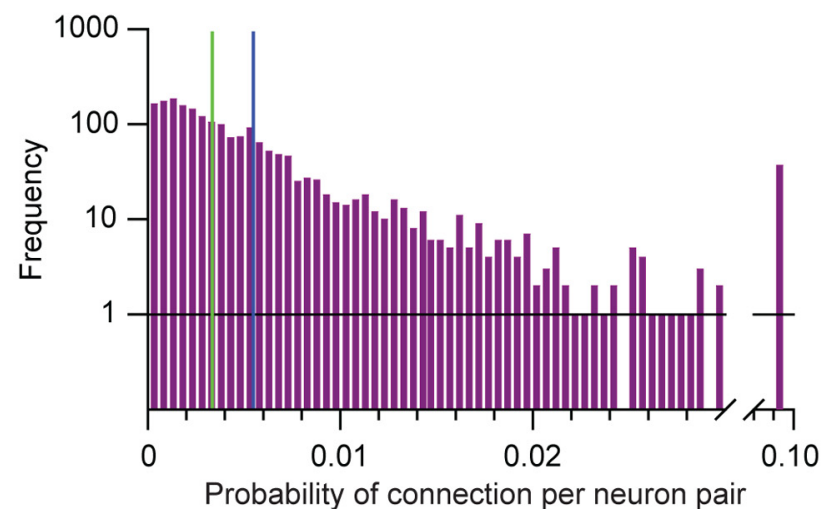

$\mathbf{F}$

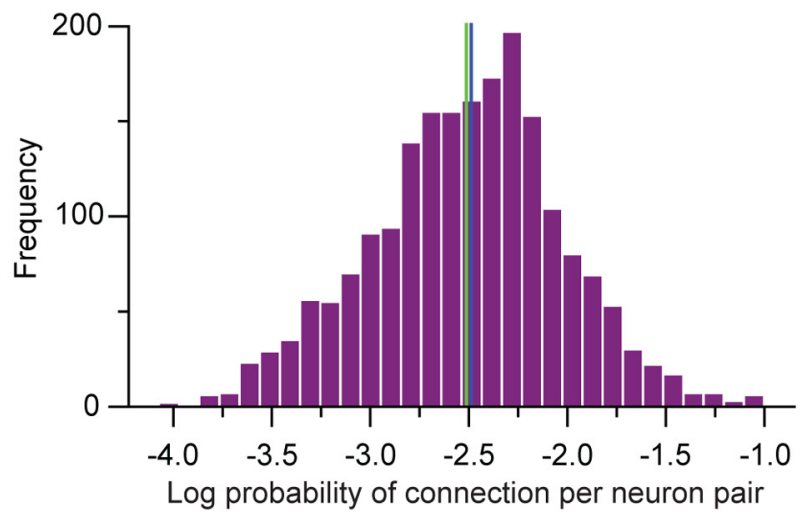

Figure 4. Connection probability by pair of presynaptic and postsynaptic neuron types. Summary plot of connection probabilities in local circuits of DG (A), CA3 (B), CA1 (C), and EC (D). Presynaptic (left horizontal axis) and postsynaptic (right horizontal axis) neuron types are labeled with numbers (black represents glutamatergic; gray represents dendritic-targeting GABAergic; blue represents perisomatic GABAergic) as coded in Extended Data Figures 2-1-2-6 and www.Hippocampome.org. For comparison with sparse estimations available in the literature, see Extended Data Figure 4-1. $\boldsymbol{E}, \boldsymbol{F}$, Distributions of axonal-dendritic connection probabilities from all 1970 analyzed pairs of neuron types across all subregions. Blue vertical lines indicate mean. Green vertical lines indicate median.

estimated probability ranges derived by our analysis. The remaining discrepancies may be explained by differences in preparation details. Specifically, the probabilities previously reported for DG mossy to DG granule included polysynaptic connections, whereas our analysis is specific for monosynaptic connections, and the CA1 PC to CA1 PC connectivity may be highly sensitive to slice orientation and intersomatic distances because of substantial cross-lamellar connectivity along the longitudinal axis (Yang et al., 2014).

\section{Number of contacts per connected neuron pair}

The number of synaptic contacts, $N_{c}$, per pair of directionally connected neurons estimated with our approach (Eq. 6), differs broadly by presynaptic neuron type and postsynaptic target but remains within a biologically reasonable range (1-15) for the vast majority (>95\%) of neuron-type pairs (Fig. 5). Over all 1970 local dendritic potential synapses examined, the number of contacts per connected pair had a mean $\pm \mathrm{SD}$ of $5.7 \pm 5.3$, a median of 4.1, and a range of 1.1-62.8 (Fig. 5A). 


\section{A Number of contacts B Dentate Gyrus C $\quad$ CA3}

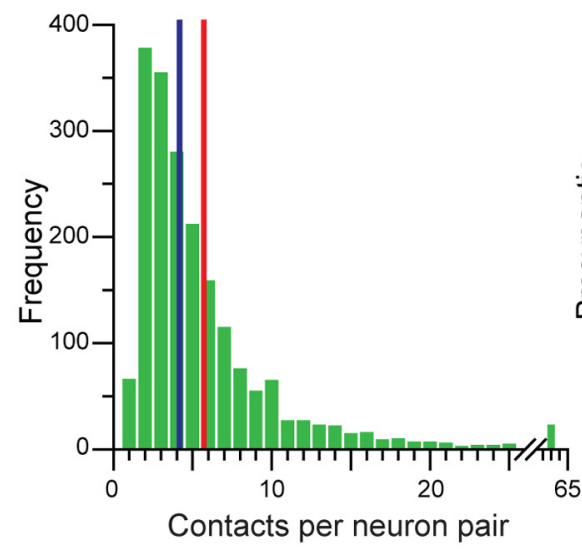

D

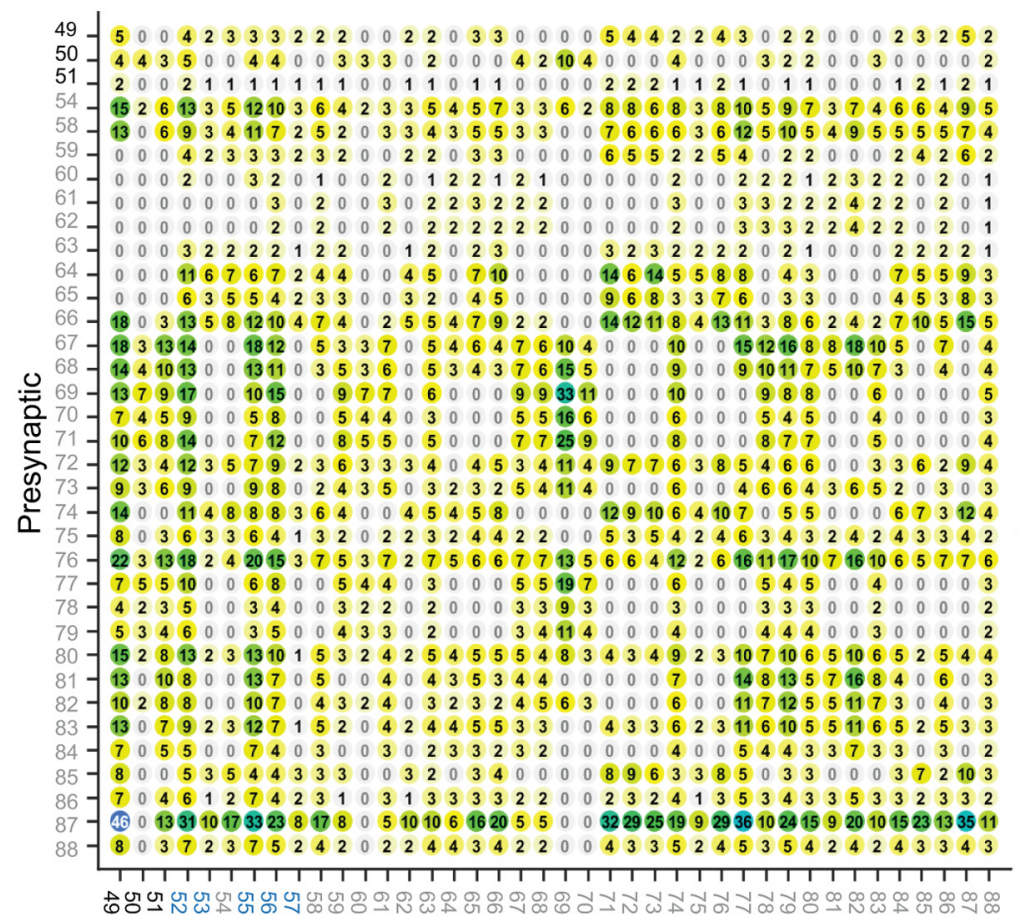

Postsynaptic

\section{$E$}

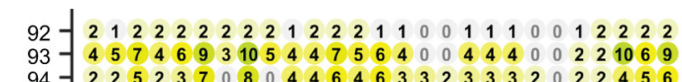

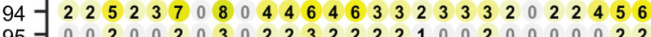

$95-\begin{array}{lllllllllllllllllllllllllll}0 & 0 & 2 & 0 & 0 & 2 & 0 & 3 & 0 & 2 & 2 & 3 & 2 & 2 & 2 & 2 & 1 & 0 & 0 & 2 & 0 & 0 & 0 & 0 & 0 & 2 & 2\end{array}$

$96-\begin{array}{llllllllllllllllllllllllllll}5 & 4 & 4 & 3 & 0 & 5 & 0 & 5 & 0 & 4 & 2 & 5 & 4 & 6 & 5 & 3 & 2 & 4 & 4 & 4 & 2 & 0 & 1 & 2 & 7 & 4 & 6\end{array}$

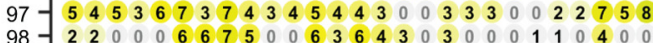

$98-\begin{array}{llllllllllllllllllllllllllll}2 & 2 & 0 & 0 & 0 & 6 & 6 & 7 & 5 & 0 & 0 & 6 & 3 & 6 & 4 & 3 & 0 & 3 & 0 & 0 & 0 & 1 & 1 & 0 & 4 & 0 & 0\end{array}$

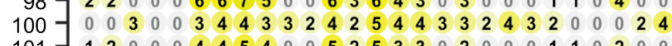

$101-1 \begin{array}{lllllllllllllllllllllllllll}1 & 2 & 0 & 0 & 0 & 4 & 4 & 5 & 4 & 0 & 0 & 5 & 2 & 5 & 3 & 3 & 0 & 2 & 0 & 0 & 0 & 1 & 1 & 0 & 2 & 0 & 0\end{array}$

.0

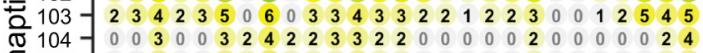

$\stackrel{0}{\leftarrow} 105-\begin{array}{lllllllllllllllllllllllllll}104 & 0 & 3 & 0 & 0 & 3 & 2 & 4 & 2 & 2 & 2 & 3 & 2 & 2 & 0 & 0 & 0 & 0 & 0 & 2 & 0 & 0 & 0 & 0 & 0 & 2 & 3\end{array}$

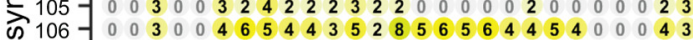

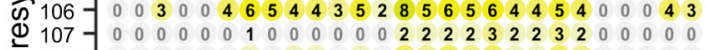

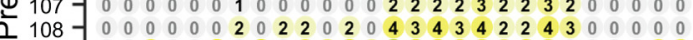

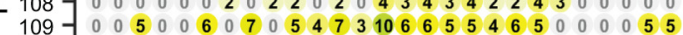

$110-10 \begin{array}{lllllllllllllllllllllllllll}0 & 0 & 0 & 0 & 0 & 0 & 2 & 0 & 0 & 0 & 0 & 0 & 0 & 4 & 3 & 3 & 3 & 4 & 2 & 2 & 4 & 3 & 0 & 0 & 0 & 0 & 0\end{array}$

$111-\begin{array}{lllllllllllllllllllllllllllll}2 & 3 & 4 & 2 & 3 & 5 & 0 & 7 & 0 & 3 & 3 & 5 & 3 & 6 & 5 & 4 & 3 & 5 & 4 & 4 & 3 & 0 & 2 & 2 & 6 & 3 & 5\end{array}$

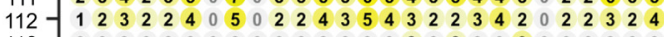

$113-\begin{array}{lllllllllllllllllllllllllll}0 & 0 & 0 & 0 & 0 & 0 & 0 & 0 & 0 & 0 & 0 & 0 & 0 & 0 & 0 & 2 & 0 & 2 & 0 & 0 & 3 & 0 & 0 & 0 & 0 & 0 & 0\end{array}$

$114-\begin{array}{llllllllllllllllllllllllllll}0 & 0 & 0 & 0 & 0 & 3 & 4 & 4 & 3 & 0 & 0 & 4 & 2 & 6 & 4 & 5 & 0 & 4 & 0 & 0 & 0 & 3 & 0 & 0 & 0 & 0 & 0\end{array}$

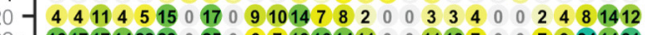

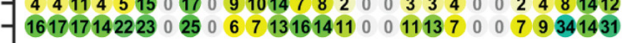

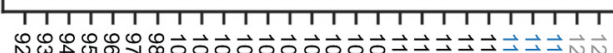

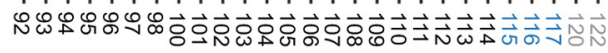

Postsynaptic

Figure 5. Number of contacts per connected pair. A, Distributions of the number of synaptic contacts per connected neuron pair from all 1970 analyzed axonal-dendritic overlaps, across all subregions. Blue vertical lines indicate mean. Red vertical lines indicate median. Number of contacts per connected pair in local circuits of DG $(\boldsymbol{B})$, CA3 $(\boldsymbol{C})$, CA1 $(\boldsymbol{D})$, and EC (E), with background colors representing the numerical values according to the heat map next to $C$. Presynaptic (vertical axis) and postsynaptic (horizontal axis) neuron types are labeled as in Figure $4 A-D$.

The relative patterns concerning the number of contacts was generally consistent across all hippocampal subregions. The average number of contacts per connected pair was systematically larger for inhibitory than for excitatory presynaptic types (DG: $6.7 \pm 0.9, n=154$ pairs vs $3.5 \pm 0.7, n=74$ pairs; CA3: $8.8 \pm 0.7$, $n=251$ pairs vs $4.0 \pm 0.7, n=56$ pairs; CA2: $8.9 \pm 2.9, n=10$ pairs vs $7.2 \pm 4.3, n=5$ pairs; CA1: $5.8 \pm 0.4, n=914$ pairs vs $2.5 \pm 0.8, n=74$ pairs; EC: $11.6 \pm 3.3, n=42$ pairs vs $3.6 \pm 0.3$, $n=384$ pairs). Moreover, in areas CA3, CA2, CA1, and Sub, the number of contacts onto excitatory cells was larger than onto inhibitory cells $(9.5 \pm 1.2, n=120$ pairs vs $5.8 \pm 0.3, n=1196$ pairs), consistent with other studies (Deuchars and Thomson, 1996; Booker and Vida, 2018). The EC and DG, however, displayed an opposite and milder trend with an average of $4.3 \pm 0.4$ contacts onto excitatory cells ( $n=420$ pairs) and $5.7 \pm 0.7$ onto inhibitory cells ( $n=234$ pairs).

Next, we compared our data with a previous estimation of the CA1 circuit (Bezaire and Soltesz, 2013). This earlier study focused on seven dendritic-targeting neuron types: Pyramidal, Bistratified, Ivy, Neurogliaform, Perforant Path-Associated, Schaffer Collateral-Associated. For every presynaptic type, they reported the total number of axonal boutons contacting two distinct postsynaptic targets: PCs and interneurons. From these data, it is possible to calculate the average number of synapses per neuron pair from each of the seven specified neuron types onto PCs and interneurons. This calculation requires an estimate of the numbers of PCs and interneurons. The aforementioned study assumes a count of 311,500 PCs and 38,500 

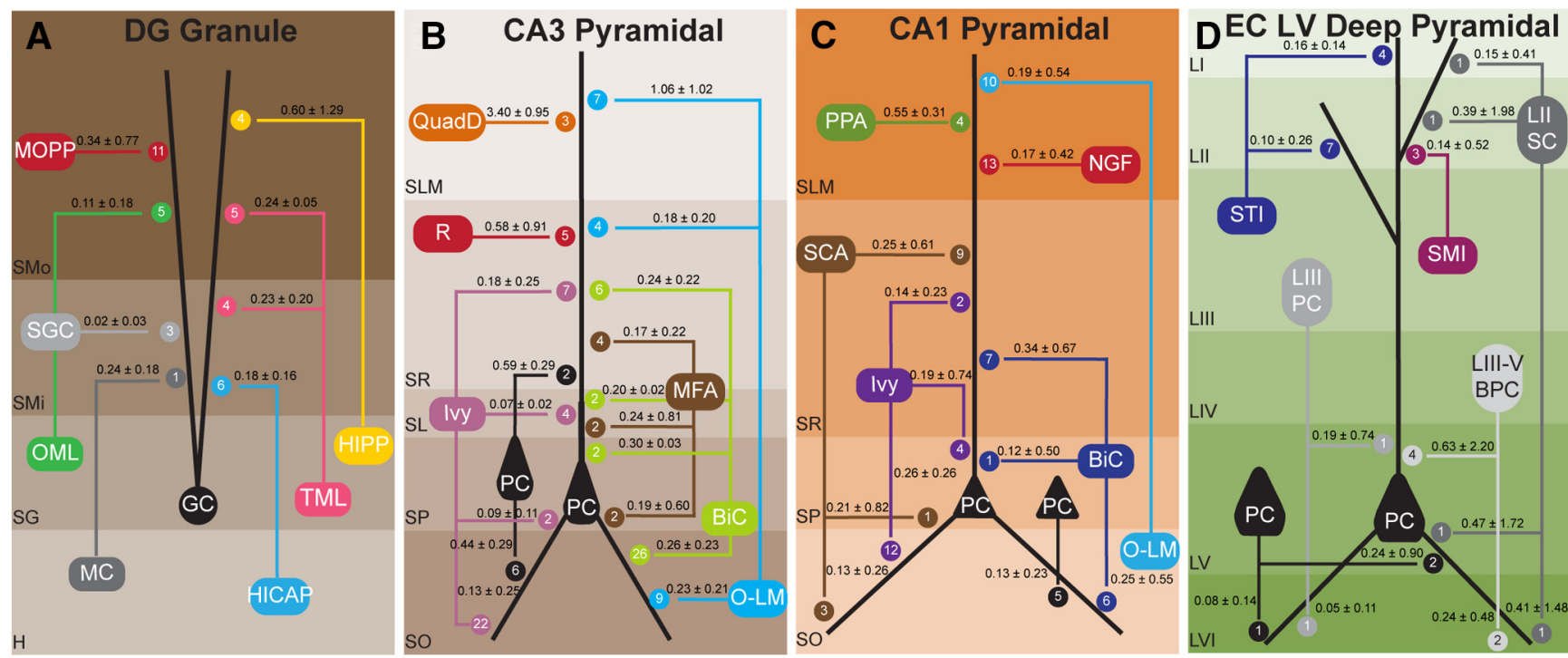

Figure 6. Representative local axonal-dendritic connections onto selected principal cells of the hippocampal formation. Circles represent numbers of contacts per connected pair. Connection probabilities \pm SDs are shown for each layer and presynaptic neuron. Black represents principal cells; gray represents other glutamatergic cells; colors represents GABAergic interneurons. $A$, Synaptic connectivity from seven different presynaptic neuron types onto DG GC. B. Synaptic connectivity from seven different presynaptic neuron types onto CA3 PC. C, Synaptic connectivity from seven different presynaptic neuron types onto CA1 PC. D, Synaptic connectivity from six different presynaptic neuron types onto EC LV deep PC. SGC, Semilunar GC; GC, Granule cell; MC, Mossy cell; HICAP, Hilar Commissural Associational Pathway-related cell; HIPP, Hilar Perforant Path-Associated cell; TML, Total Molecular Layer cell; OML, Outer Molecular Layer cell; MOPP, MOlecular layer Perforant Path-associated cell; MFA, Mossy Fiber-Associated cell; QuadD, Quadrilaminar; R, Radiatum cell; BiC, Bistratified cell; NGFC, Neurogliaform cell; PPA, Perforant-PathAssociated cell; SCA, Schaffer Collateral-Associated cell; LIII-V BPC, LIII-V Bipolar PC; LII SC, MEC LII Stellate cell; STI, MEC LIII Superficial Trilayered Interneuron; SMI, MEC LIII Superficial Trilayered Interneuron cell; SMi, inner one-third of stratum moleculare; SG, stratum granulosum; H, hilus.

interneurons in the adult rat CA1. Whereas the former value is consistent with contemporary literature (Herculano-Houzel et al., 2011; Murakami et al., 2018), recent reports suggest a more than doubled abundance of interneurons (Erö et al., 2018). We thus used a number of 77,000 interneurons and compared the so-derived average number of synapses per neuron pair with the corresponding quantities independently obtained in the present work (Extended Data Fig. 5-1). The two sets of values are significantly correlated $(R=0.73, p<0.0002)$, and the best fitting line with zero intercept has a slope close to unity $(0.91$ with the data derived from Bezaire and Soltesz, 2013 as ordinate and the data from current study as abscissa).

We had previously estimated the number of contacts per connected pair in selected neuron types of the CA3 circuit based on in vivo morphologic reconstructions embedded in a $3 \mathrm{D}$ model of the hippocampal formation (Ropireddy and Ascoli, 2011). That earlier study had quantitatively differentiated two distinct components of the "recurrent collateral" connectivity between CA3 PCs. Specifically, postsynaptic PCs were found to receive a higher number of contacts from presynaptic PCs located in the distinct subfield CA3c $(5.6 \pm 0.2)$ than from CA3 PC in the rest of area CA3 (3.4 \pm 0.3$)$. The approach given in the present work confirms the same qualitative difference, with the number of contacts from CA3c PCs exceeding those from other CA3 PCs 1.49 - to 1.97 -fold in the range of interaction radius used in the two reports (Ropireddy and Ascoli, 2011: $1 \mu \mathrm{m}$; current study: $2 \mu \mathrm{m})$. Together, our results are thus well aligned with the very sparse existing literature estimates while substantially extending them to the majority of local connections throughout the hippocampal formation.

\section{Quantification of trisynaptic circuit}

The connection probabilities and numbers of contacts per connected pair allow us to derive a quantitative summary of synaptic connectivity by layer onto the principal cells of the main subregions of the hippocampal formation (Fig. 6). While this analysis is limited to axonal-dendritic interactions in the local circuit (and the Fig. 6 schematic only illustrates selected presynaptic neuron types), a full understanding of the hippocampal network also requires similar data for projection and perisomatic presynaptic neuron types. For completeness, we thus collated the available experimental evidence for these complementary cases (Extended Data Fig. 6-1; Szabadics et al., 2009; Ganter et al., 2004; Gloveli et al., 2005b). Of 60 pairs of neuron types with available data, connection probabilities were reported or derivable in only 10 cases, and numbers of contacts per connected pair in 16. In most other cases, the synaptic connections were confirmed to exist, but not quantified.

On the one hand, this compilation identifies a set of "unknown parameters" that are important for computational simulations but have yet to be measured experimentally. On the other, it may allow the community to extend, update, and complement the existing quantitative knowledge of the hippocampal network. According to previous measurements of the CA1 local circuit in vitro (Takács et al., 2012), 29.3\% of CA1 PC boutons contact other CA1 PCs, $65.9 \%$ contact interneurons, and $4.9 \%$ of local synapses are made onto unknown targets. However, experimental evidence from cells labeled in vivo yields different percentages (46.2\% interneurons, 39.2\% CA1 PCs, 6.9\% unknown targets) and more heterogeneous distributions. In terms of extrinsic inputs, the same study shows that Schaffer collaterals preferentially target CA1 PCs (92.9\%) over interneurons (7.1\%), whereas EC temporo-ammonic axons in CA1 SLM predominantly contact PC dendrites (90.8\%).

\section{Laminar distributions of axonal and dendritic path distances from the soma}

To determine the distance from the soma of potential synapses along the presynaptic and postsynaptic neural arbors, we measured the layer-specific distributions of the minimum, mean, and 

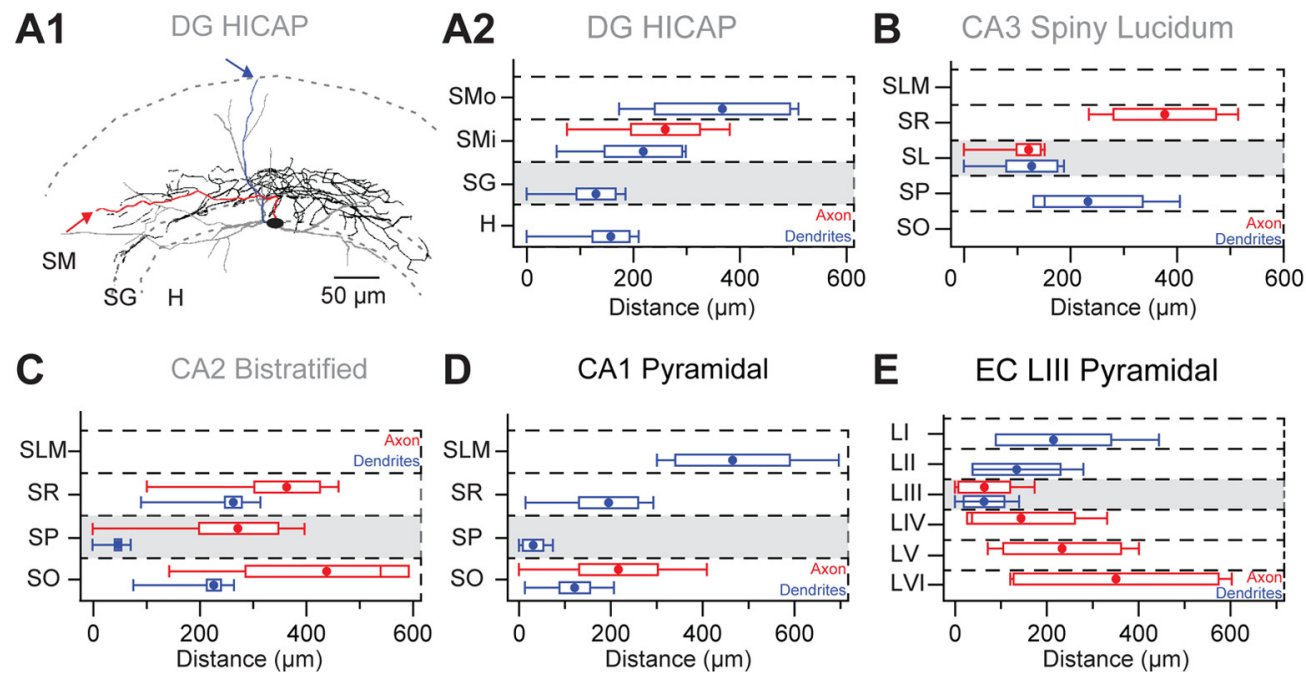

Figure 7. Mean distances from the soma. A1, DG HICAP interneuron (Reproduced from Mott et al., 1997) highlighting the path tracing axons in SMi (red) and dendrites in SMo (blue), starting from the soma (black). A2, Layer-specific axonal and dendritic distances from the soma for DG HICAP interneurons $(n=4)$. Middle dot indicates mean. Box boundaries represent SD. Whiskers represent minimum and maximum values. Gray represents somatic layer. $\boldsymbol{B}$, Layer-specific axonal and dendritic distances from the soma for $C A 3$ Spiny Lucidum interneurons $(n=5)$. C, Layer-specific axonal and dendritic distances from the soma for CA2 Bistratified interneurons $(n=6)$. $\boldsymbol{D}$, Layer-specific axonal and dendritic distances from the soma for CA1 PCs ( $\boldsymbol{D}$ : $n=15$; $A: n=8)$. $\boldsymbol{E}$, Layer-specific axonal and dendritic distances from the soma for EC LIII PCS $(n=5)$. Black represents glutamatergic neurons; gray represents GABAergic. SMi, Inner one-third of stratum moleculare; SG, stratum granulosum; H, hilus; SLM, stratum lacunosum-moleculare; SR, stratum radiatum; SL, stratum lucidum; SP, stratum pyramidale; S0, stratum oriens; SMo, outer two-thirds of stratum moleculare.

maximum axonal and dendritic paths distances from the somatic origin for every neuron type. Here we illustrate the results for representative cells in DG, CA3, CA2, CA1, and EC (Fig. 7). The measurements for all analyzed neuron types are available at www.hippocampome.org/php/synapse_probabilities.php. As expected, path distances tended to increase moving away from the somatic layer. However, the range of distances within each layer was substantially broad and, in most cases, larger than the difference between layers.

We then compared the estimated postsynaptic somatic distances of CA3 PC with the distribution of potential synapses onto dendrites of the same neuron types previously derived from embedding morphologic reconstructions into a 3D hippocampal model (Ropireddy and Ascoli, 2011, their Figs. 5C, 6E). In SO, the synaptic distance from the soma along the dendritic path of CA3 PCs obtained in the present work $(128.5 \pm 51.2 \mu \mathrm{m})$ tightly matched the distribution of potential synapses on CA3 PC basal dendrites from the earlier study $(110-160 \mu \mathrm{m})$. In SR, the dendritic distance from the present work $(256.4 \pm 64.7 \mu \mathrm{m})$ also yielded an excellent correspondence with the Ropireddy and Ascoli (2011) distribution of potential synapses on CA3 PC apical dendrites $(200-320 \mu \mathrm{m})$. Last, in SLM, the dendritic distance from the soma derived here $(507.1 \pm 130.1 \mu \mathrm{m})$ was consistent with the distribution of inhibitory synapses from GABAergic interneurons on the apical tuft of CA3 PCs $(500-750 \mu \mathrm{m})$.

\section{Public digital resource and online data accessibility}

All connection probabilities and numbers of contacts per connected pair, for each of the 1970 pairs of neuron types analyzed here, as well as the (644) parcel-specific axonal and dendritic lengths and (568) somatic path distances for every neuron type, are publicly posted on www.Hippocampome.org, increasing the count of Pieces of Knowledge of this resource by 5152 . The published evidence underlying all values, including 1181 neurite lengths, 3663 path lengths, 1091 convex hull volumes, 94 slice thicknesses, and 26 parcel volumes, are also directly accessible through the web portal, amounting to a total of 6055 additional Pieces of Evidence in this public knowledge base.

Specifically, the "Synapse Probability" option in the dropdown menu of the www.Hippocampome.org "Browse" tab provides a compendium of companion web pages associated with this research that allow users to interactively explore the results (Fig. 8). Users can find specific data related to their research interests, such as the distances along dendrites and axons measured from the soma, by selecting a value associated with the desired neuron type and parcel (Fig. 8A). Each value is linked to an evidence page, which displays the supporting quotes, figures, and measurements (in this specific example, of somatic distances) found in each individual supporting article (Fig. 8A1,A1b). By selecting a presynaptic neuron type and a postsynaptic neuron type (Fig. $8 B$ ), researchers can gain information about connection probabilities and numbers of contacts per connected pair in each parcel (Fig. 8B1) and inspect the evidence used to generate the data (Fig. 8B2), such as neurite lengths (Fig. 8B2a, $B 2 b$ ) and convex hull volumes. All the estimations are available to download in comma-separated value files that contain matrix values and further statistics (Fig. 8C). Finally, we provide a tool allowing investigators to choose their own desired values for the ultrastructural parameters (distance between axonal boutons, distance between dendritic spines or postsynaptic locations, and interaction radius) and then obtain parcel-specific connection probabilities and numbers of contacts per connected pair for any selection of neuron types (Fig. 8D,D1).

\section{Discussion}

Despite a continuous growth of information pertaining to the morphology, electrophysiology, and gene expression of neurons in mammalian brains, direct experimental evidence for quantifying neuron type-specific synaptic connectivity remains exceedingly sparse, even in the most intensively investigated neural systems, such as the rodent hippocampal formation. Here, we have introduced a novel pipeline to produce a zero-order 


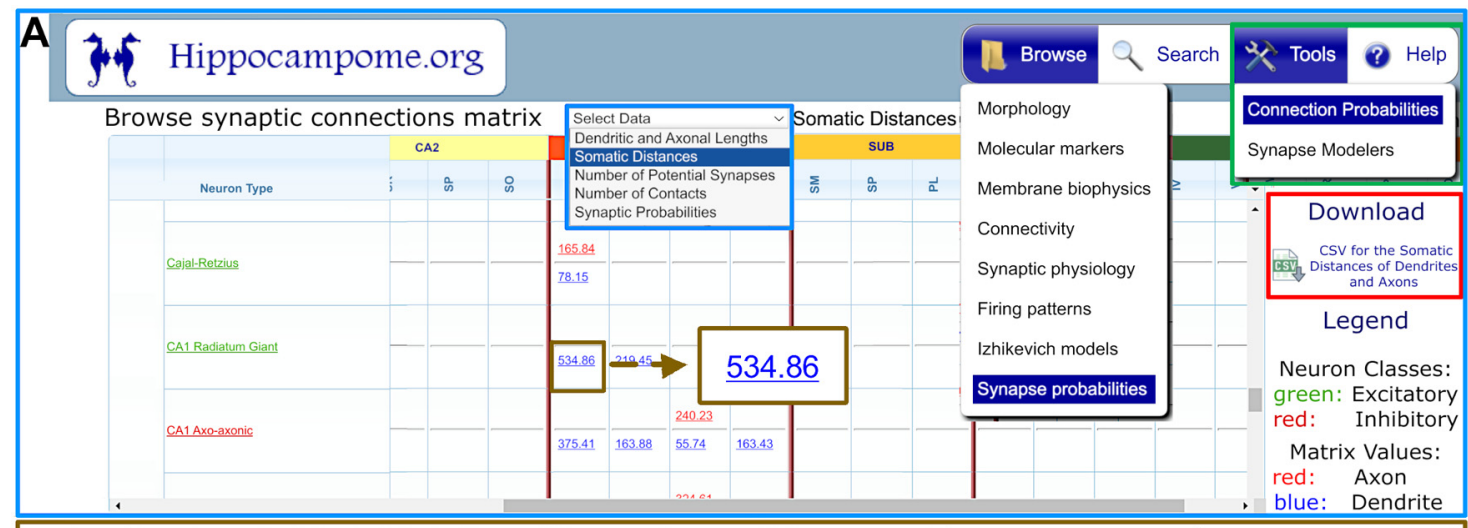

\begin{tabular}{|c|c|}
\hline $1 \nabla$ & $\begin{array}{l}\text { Long-term potentiation in distinct subtypes of hippocampal nonpyramidal neurons. } \\
\text { Maccaferri G, McBain CJ. J Neurosci, } 1996 \text { Sep 1, } 16 \text { (17), pages: } 5334 \text { - } 5343 \\
\text { PMID: 8757246; }\end{array}$ \\
\hline & $\begin{array}{l}\text { Somatic distances of dendrites: mean } 263.67 \pm \text { standard deviation } 9.04(n=3 \text {; } \\
\min =82.84 ; \max =460.52)\end{array}$ \\
\hline & RAR compressed somatic-distance paths for CA1:SLM:D: \\
\hline & Page location: p5340, Fig5A1 \\
\hline & $\begin{array}{l}\text { Figure 5. Basic morphological and electrophysiological characteristics of RGs. } \\
\text { A1-A3 show camera lucida drawings from representative cells of this class. } \\
\text { Calibration bar, } 50 \text { [micro]m. Note the triangular cell body from which two main } \\
\text { diverging dendritic shafts emerge and the axon collateral ramifying in st. oriens/ } \\
\text { alveus (arrows). }\end{array}$ \\
\hline
\end{tabular}
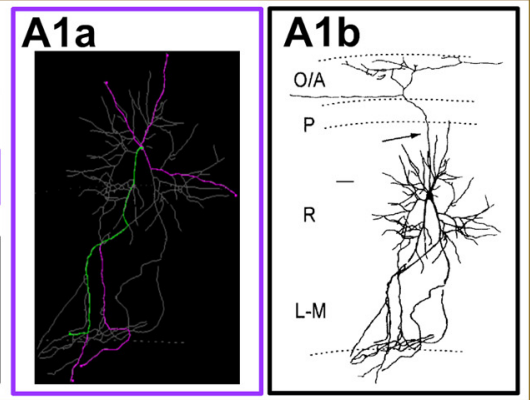

B Browse synaptic connections matrix Select Data Number of Contacts

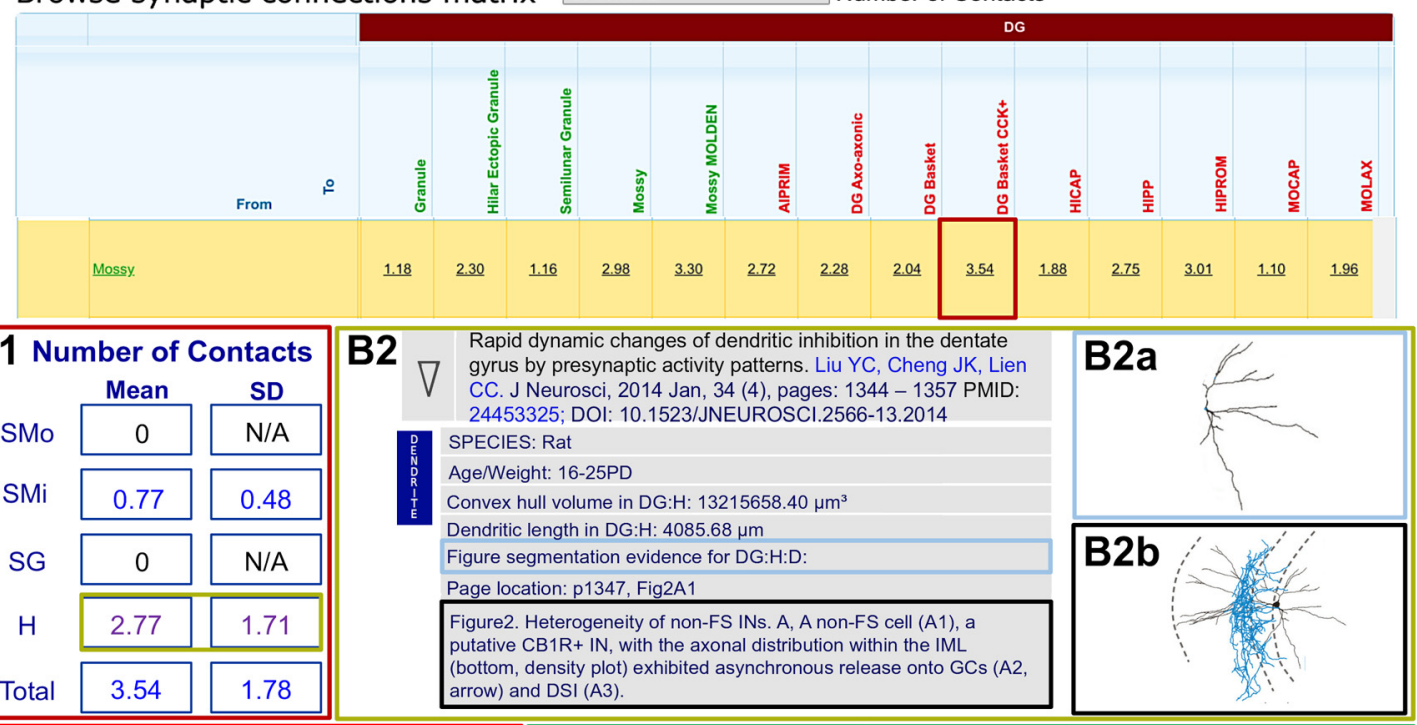

C Neuron,Parcel,Avg,SD,Count,Min,Max

CA1 Radiatum Giant,CA1:SLM:D,534.86,

$166.58,12,82.84,810.49$

CA1 Radiatum Giant,CA1:SR:D,219.45,

$82,12,0.0,641.11$

CA1 Radiatum Giant,CA1:SO:A,432.65,

$97.41,8,254.22,955.20$

\begin{tabular}{|c|c|c|c|c|c|c|}
\hline \multirow{2}{*}{$\begin{array}{l}\mathbf{D}_{\text {Presynaptic }} \\
\text { Postsynaptic }\end{array}$} & \multirow{2}{*}{$\begin{array}{l}\text { DG Hilar Ectopic Granule } \\
\text { DG AIPRIM }\end{array}$} & \multirow{2}{*}{\begin{tabular}{|l|} 
D1 \\
SMo \\
\end{tabular}} & \multicolumn{4}{|c|}{$\begin{array}{l}\text { Probability Contacts } \\
\text { Mean SD Mean SD }\end{array}$} \\
\hline & & & 0 & N/A & 0 & $\mathrm{~N} / \mathrm{A}$ \\
\hline Dendritic snine disfance (um) & (1) & SMi & 0 & N/A & 0 & $\mathrm{~N} / \mathrm{A}$ \\
\hline & & SG & 0 & N/A & 0 & N/A \\
\hline Inter-bouton distance $(\mu \mathrm{m})$ & 4.7 & $\mathrm{H}$ & 0.004 & 0.006 & 13.9 & 20.4 \\
\hline Radius of interaction $(\mu \mathrm{m})$ & 5 & Total & 0.004 & 0.006 & 13.9 & 20.4 \\
\hline
\end{tabular}

Figure 8. Interactive browsing and downloading of data associated with the quantification of neurites and potential synaptic connectivity on www. Hippocampome.org. $\boldsymbol{A}$, Representative screenshot of a www.Hippocampome.org data matrix. The drop-down menu (light blue box) provides options to display dendritic and axonal lengths, somatic distances, average numbers of potential synapses, numbers of contacts per connected pair, and connection probabilities. Green-outlined box represents the Connection Probabilities tool. Red box highlights the download section for the data. The representative entry in the brown box, enlarged in the dark blue box, corresponds to the somatic distances along the dendrite for a CA1 Radiatum Giant cell in SLM. A1, Bibliographic evidence underlying the reported somatic distance. A1a, Depiction of the dendrites measured to determine the above distance value. A1b, Source figure from which $\mathbf{A 1 a}$ is derived. $\boldsymbol{B}$, Section of the "number of contacts" matrix. Dark red box highlights the number of contacts between presynaptic Mossy and postsynaptic Basket CCK ${ }^{+}$, whose parcel-specific values are shown in $\boldsymbol{B 1}$. B2, Bibliographic evidence for the selected number of contacts per connected pair and illustration of the neurites isolated in computing the number of contacts for the selected parcel $(\boldsymbol{B} \mathbf{2} \boldsymbol{a})$ and the corresponding source image $(\boldsymbol{B} \mathbf{2} \boldsymbol{b})$. $\boldsymbol{C}$, Users can download all values from the matrix in comma-spaced-value format. $\boldsymbol{D}$, The Connection Probabilities tool is used to find connection probabilities and numbers of contacts from user-supplied ultrastructural parameter values for a given pair of neurons. D1, The results are computed for all of the local layers involved in the connection between the two selected neuron types. 
approximation of the connection probability, number of contacts per connected pair, and presynaptic and postsynaptic somatic distances for most pairs of potentially connected neuron types in the local circuits of the hippocampus and EC. While this initial order-of-magnitude estimate of connectivity will undoubtedly require successive quantification refinements, our results nonetheless constitute a remarkably comprehensive characterization of nearly 2000 neuron-type connections. This dataset provides a useful placeholder for computational modeling and network analyses until firmer empirical measurements are collected and released (Ascoli and Atkeson, 2005). Notably, biologically realistic simulations of the hippocampal circuit will also require a complete neuron census, that is, the count of neurons within each type (Attili et al., 2019).

\section{From morphology to function: synaptic count and implications for local circuits}

The framework introduced in this study focuses on axonal-dendritic connections, thus excluding perisomatic synapses that only constitute a minority $(\sim 6 \%)$ of the hippocampal connectivity (Megías et al., 2001). Moreover, our approach is limited to the local circuit, as captured by typical slice preparations from which most available morphologic data are derived. While recent technological advancements now allow the systematic $3 \mathrm{D}$ reconstruction of long-range single-neuron axonal projections (Winnubst et al., 2019), that process is still too slow to yield dense coverage of the needed data, and currently only provides access to a small proportion $(<4 \%)$ of neuron types in the mouse hippocampal formation. In contrast, representative local two-dimensional morphologic tracings are available for 115 of the 122 distinct neuron types identified by www.Hippocampome.org. The seven missing reconstructions (three in CA3 and four in EC) account for 250 connections, representing only $11 \%$ of the 2206 neuron type pairs potentially connected by local axonal-dendritic synapses. At the same time, as additional neuron types are likely to be discovered in the future, continuous screening of neuronal morphologies will be required to maintain this information up to date.

Peters' rule assumes that the overlap of presynaptic axons with postsynaptic dendrites is equivalent to the probability of synaptic connectivity in the absence of targeting preference (Peters and Feldman, 1976). Experimental evidence in the neocortex indicates that interneuron axons have smaller branch lengths and higher tortuosity compared with PCs, suggesting greater specificity in their targeting of postsynaptic neurons (Stepanyants et al., 2004). Furthermore, while the number of actual synapses made by PCs is just a fraction (10\%-30\%) of all axonal-dendritic overlaps (Stepanyants et al., 2002), our estimated count of presynaptic and postsynaptic elements based on interbouton and interspine distances, respectively, already corrects for this factor.

Importantly, axonal and dendritic morphology in the rodent hippocampal formation has been proven to correctly predict circuit connectivity at the neuron-type level (Rees et al., 2017), at an accuracy of $99 \%$, when exceptions are made for axo-axonic and interneuron-specific connections. For example, the predominant local connections from CA1 PCs to CA1 O-LM cells and other interneurons with horizontal dendritic arbors at the border of SO and the alveus (Maccaferri, 2005) are a consequence of Peters' rule: CA1 O-LM cells and these other SO interneurons receive $\sim 70 \%$ of their glutamatergic input from CA1 PCs (Blasco-Ibáñez and Freund, 1995). Still, proven synaptic specificity, such as that for axo-axonic and interneuron-specific connections, takes precedence over Peters' rule in our framework: in other words, we excluded experimentally refuted connections from the calculations of connection probability and number of contacts per connected pair.

Among all analyzed subregions, CA2 had the highest connection probability, by nearly an order of magnitude (weighted average for CA2: $0.048, n=15$ neuron type pairs; weighted average for the rest of the hippocampal formation: 0.0053, $n=1955$ ). This may be due, at least in part, to the smaller total volume of CA2 compared with other areas (CA2: $2.28 \mathrm{~mm}^{3}$; CA1: 30.13 $\mathrm{mm}^{3}$ ): we calculate connection probabilities based on axonaldendritic overlap density, thus resulting in higher values for CA2 given similar axonal-dendritic extents. CA1 exhibits shorter axonal lengths within the local circuit on top of the greater volume. The small number of known neuron types in CA2 nonetheless urges interpretative caution. At the same time, connection probability is often correlated to synaptic amplitude (Jiang et al., 2015); and amplitudes are indeed larger in CA2 than in CA1 neurons (Kohara et al., 2014; Sun et al., 2014), suggesting that our finding is not artifactual.

The neurite length analysis presented here also showed that the principal cells of the Sub, the CA1-projecing PCs, exhibit substantial axonal extensions in the polymorphic layer $(4543.9 \mu \mathrm{m})$, although there are no known neuron types extending dendrites in that layer. This observation invites two alternative explanations. One is the existence of yet undiscovered neuron types that can receive the mentioned inputs. In general, the Sub local circuit remains largely unexplored, and there is growing evidence supporting the idea of new cell types (Menendez de la Prida et al., 2003; Witter, 2006; Kinnavane et al., 2018). The other possibility is that this layer might be a mere transition zone for axonal projections to reach other areas.

The involvement of gap junctions in the hippocampal formation is associated with neuronal synchronization during oscillatory activity, mainly between GABAergic parvalbumin-positive interneurons (Ylinen et al., 1995; Fukuda and Kosaka, 2000; Baude et al., 2007). Recent evidence showed that gap junctions are present in the adult hippocampus between glutamatergic cells as mixed synapses but remain mainly closed under control conditions $(<10 \%)$ and require acidic changes in intracellular $\mathrm{pH}$ to increase the opening probability (Ixmatlahua et al., 2020). Additional experimental evidence should be collected to address the role of gap junctions during nonrhythmic activity and for inclusion in circuitry estimates.

\section{Path tracing and synaptic attenuation}

Temporal neuronal dynamics depend on axonal delays as well as on the attenuation of evoked postsynaptic potentials across the dendritic tree. Because axonal spikes propagate at approximately constant velocity (Rama et al., 2018), presynaptic signal delay is essentially proportional to the somatic path distance to the release sites. Dendrites are constantly receiving synaptic inputs and signals may be enhanced or reduced according to their locations (Destexhe and Paré, 1999; Maccaferri et al., 2000; Ferrante et al., 2013). These effects are the result of multiple factors that change as a function of the distance from the soma along the arbor path, such as internal resistivity, resting membrane potential, and receptor expression, activation, conductance, and modulation (Magee, 1998; Golding et al., 2005; Grillo et al., 2018). We estimated the mean axonal and dendritic distance from the soma across every layer. Another key influence on signal attenuation is exerted by branch diameter, which can vary substantially between layers (Megías et al., 2001) but has not been assessed yet 
for many neuron types. The distal dendritic diameter of hippocampal neurons is often near the resolution limit of traditional light microscopy, and its measurement is notoriously unreliable (Scorcioni et al., 2004).

\section{Limitations and confounds}

Our approach to calculating linear-length estimations of axons and dendrites for all www.Hippocampome.org neuron types is constrained by the relatively small number of reconstructions available in the peer-reviewed literature. In order to circumvent this limitation, we collated neuronal reconstructions from several different strains of both mice and rats (Extended Data Fig. 2-7). In the absence of comparative morphologic data for specific neuron types, we adopted a conversion factor equal to the cubic root of the volume scaling parameter from mouse to rat (West et al., 1978). In contrast, we did not perform any correction for the different strains used, as a comparison of different rat atlases indicates that the hippocampal formation remains remarkably consistent across strains (Kjonigsen et al., 2015). Another large effect on neurite length and anatomic volume pertains to the age of the animals. To compensate for this known source of variability, we applied a scaling factor to normalize the measurements from young to adult animals (Juárez et al., 2008).

The variety of labeling methods are also likely to cause significant differences in observed morphologic features, even within the same neuron type (Farhoodi et al., 2019). New approaches to identify neuron populations, such as genetic barcoding, will provide improved specificity to describe the properties and dynamics associated with different neuron types and their functional role in neuronal circuits (Sugino et al., 2019). Techniques, such as octuple patch-seq recordings, optogenetics and labeling, and serial-block-face scanning electron microscopy, will continue to fill the gaps in the experimental acquisition of electrophysiology, connectivity, morphology, and transcriptomics for a large set of different neuron types (Jiang et al., 2015; Cadwell et al., 2016). However, the existing experimental toolsets still lack the scalability and specificity needed to classify all identified neuron types at www.Hippocampome.org. More accurate and unbiased labeling techniques are required to completely characterize neuron type populations and morphologies.

Another issue to consider is the completeness of the reconstructions. Tracings from slices are necessarily incomplete if the maximal span of the axonal or dendritic trees exceeds the slice thickness (Uylings et al., 1986; Parekh et al., 2015). Unfortunately, the depth from the slice surface to the recording neuron is seldom reported in peer-reviewed publications. Slicing orientation can also heavily affect the physical integrity of neural arbors. Ideally, different sectioning angles should be used to obtain optimal axonal reconstruction (E. Harris et al., 2001; Gloveli et al., 2005a). For example, hippocampal-EC slices preserve the fibers from the perforant path, mossy fibers, and Schaffer collaterals, whereas coronal slices only preserve Schaffer collateral fibers (Xiong et al., 2017). Interestingly, while some authors showed in silico that the completeness of axonal collaterals remains constant independent of slice orientation (Guzman et al., 2016), other studies report that axonal collateral densities in $400 \mu \mathrm{m}$ coronal slices are discontinuous with the cell body (Li et al., 1993). In general, axonal reconstructions can rarely be considered complete in any slice preparation. Therefore, the data reported here, largely sourced from slices, are likely underestimates of in vivo connectivity (Extended Data Table 1-2).
In conclusion, detailed modeling of hippocampal circuits with biologically realistic neural network simulations requires quantitative information related to identified neuron types. Our estimations constitute the first attempt to fill in the gaps about the connection probabilities and numbers of contacts per connected pair between different neuron types in an approximate but comprehensive manner, until further direct experimental data become available. We also measured the layer-specific axonal and dendritic distances from the soma, which can be used to determine temporal integration of signals during circuit-related activity in distinct neuron types by electrotonic propagation and axonal delay along the neurites.

\section{References}

Acsády L, Arabadzisz D, Freund TF (1996a) Correlated morphological and neurochemical features identify different subsets of vasoactive intestinal polypeptide-immunoreactive interneurons in rat hippocampus. Neuroscience 73:299-315.

Acsády L, Görcs TJ, Freund TF (1996b) Different populations of vasoactive intestinal polypeptide-immunoreactive interneurons are specialized to control pyramidal cells or interneurons in the hippocampus. Neuroscience 73:317-334.

Ali AB, Bannister AP, Thomson AM (1999) IPSPs elicited in CA1 pyramidal cells by putative basket cells in slices of adult rat hippocampus. Eur J Neurosci 11:1741-1753.

Amirikian B (2005) A phenomenological theory of spatially structured local synaptic connectivity. PLoS Comput Biol 1:e11.

Andersen P, Bliss TV, Skrede KK (1971) Lamellar organization of hippocampal excitatory pathways. Exp Brain Res 13:222-238.

Anderson WD, Galván EJ, Mauna JC, Thiels E, Barrionuevo G (2011) Properties and functional implications of Ih in hippocampal area CA3 interneurons. Pflugers Arch 462:895-912.

Armstrong C, Szabadics J, Tamás G, Soltesz I (2011) Neurogliaform cells in the molecular layer of the dentate gyrus as feed-forward $\gamma$-aminobutyric acidergic modulators of entorhinal-hippocampal interplay. J Comp Neurol 519:1476-1491.

Ascoli GA, Atkeson JC (2005) Incorporating anatomically realistic cellularlevel connectivity in neural network models of the rat hippocampus. Biosystems 79:173-181.

Attili SM, Silva MF, Nguyen T, Ascoli GA (2019) Cell numbers, distribution, shape, and regional variation throughout the murine hippocampal formation from the adult brain Allen Reference Atlas. Brain Struct Funct 224:2883-2897.

Bannister NJ, Larkman AU (1995) Dendritic morphology of CA1 pyramidal neurones from the rat hippocampus: I. Branching patterns. J Comp Neurol 360:150-160.

Bartos M, Vida I, Frotscher M, Geiger JR, Jonas P (2001) Rapid signaling at inhibitory synapses in a dentate gyrus interneuron network. J Neurosci 21:2687-2698.

Bartos M, Vida I, Frotscher M, Meyer A, Monyer H, Geiger JR, Jonas P (2002) Fast synaptic inhibition promotes synchronized gamma oscillations in hippocampal interneuron networks. Proc Natl Acad Sci USA 99:13222-13227.

Bartos M, Sauer J, Vida I, Kulik Á (2010) Fast and slow GABAergic transmission in hippocampal circuits. In: Hippocampal microcircuits, pp 129161. New York: Springer.

Baude A, Bleasdale C, Dalezios Y, Somogyi P, Klausberger T (2007) Immunoreactivity for the GABAA receptor alphal subunit, somatostatin and Connexin 36 distinguishes axoaxonic, basket, and bistratified interneurons of the rat hippocampus. Cereb Cortex 17:2094-2107.

Bauer EP, Paz R, Pare D (2007) Gamma oscillations coordinate amygdalorhinal interactions during learning. J Neurosci 27:9369-9379.

Bell LA, Bell KA, McQuiston AR (2013) Synaptic muscarinic response types in hippocampal CA1 interneurons depend on different levels of presynaptic activity and different muscarinic receptor subtypes. Neuropharmacology 73:160-173

Bezaire MJ, Soltesz I (2013) Quantitative assessment of CA1 local circuits: Knowledge base for interneuron-pyramidal cell connectivity. Hippocampus 23:751-785. 
Blasco-Ibáñez JM, Freund TF (1995) Synaptic input of horizontal interneurons in stratum oriens of the hippocampal CA1 subfield: structural basis of feed-back activation. Eur J Neurosci 7:2170-2180.

Booker SA, Vida I (2018) Morphological diversity and connectivity of hippocampal interneurons. Cell Tissue Res 373:619-641.

Buckmaster PS (2012) Mossy cell dendritic structure quantified and compared with other hippocampal neurons labeled in rats in vivo. Epilepsia, 53 Suppl 1(Suppl 1), 9-17.

Buckmaster PS, Strowbridge BW, Kunkel DD, Schmiege DL, Schwartzkroin PA (1992) Mossy cell axonal projections to the dentate gyrus molecular layer in the rat hippocampal slice. Hippocampus 2:349-362.

Buhl EH, Han ZS, Lorinczi Z, Stezhka VV, Karnup SV, Somogyi P (1994) Physiological properties of anatomically identified axo-axonic cells in the rat hippocampus. J Neurophysiol 71:1289-1307.

Burgalossi A, Herfst L, von Heimendahl M, Förste H, Haskic K, Schmidt M, Brecht M (2011) Microcircuits of functionally identified neurons in the rat medial entorhinal cortex. Neuron 70:773-786.

Cadwell CR, Palasantza A, Jiang X, Berens P, Deng Q, Yilmaz M, Reimer J, Shen S, Bethge M, Tolias KF, Sandberg R, Tolias AS (2016) Electrophysiological, transcriptomic and morphologic profiling of single neurons using Patch-seq. Nat Biotechnol 34:199-203.

Canto CB, Witter MP (2012a) Cellular properties of principal neurons in the rat entorhinal cortex: I. The lateral entorhinal cortex. Hippocampus 22:1256-1276.

Canto CB, Witter MP (2012b) Cellular properties of principal neurons in the rat entorhinal cortex: II. The medial entorhinal cortex. Hippocampus 22:1277-1299.

Canto CB, Wouterlood FG, Witter MP (2008) What does the anatomical organization of the entorhinal cortex tell us? Neural Plast 2008:381243.

Chamberland S, Salesse C, Topolnik D, Topolnik L (2010) Synapse-specific inhibitory control of hippocampal feedback inhibitory circuit. Front Cell Neurosci 4:130.

Claiborne BJ, Amaral DG, Cowan WM (1986) A light and electron microscopic analysis of the mossy fibers of the rat dentate gyrus. J Comp Neurol 246:435-458.

Coddington LT, Rudolph S, Vande Lune P, Overstreet-Wadiche L, Wadiche JI (2013) Spillover-mediated feedforward inhibition functionally segregates interneuron activity. Neuron 78:1050-1062.

Coleman PD, Flood DG, West MJ (1987) Volumes of the components of the hippocampus in the aging F344 rat. J Comp Neurol 266:300-306.

Colgin LL (2016) Rhythms of the hippocampal network. Nat Rev Neurosci $17: 239-249$

Couey JJ, Witoelar A, Zhang SJ, Zheng K, Ye J, Dunn B, Czajkowski R, Moser MB, Moser EI, Roudi Y, Witter MP (2013) Recurrent inhibitory circuitry as a mechanism for grid information. Nat Neurosci 16:318-324.

Craig MT, McBain CJ (2015) Fast gamma oscillations are generated intrinsically in CA1 without the involvement of fast-spiking basket cells. J Neurosci 35:3616-3624.

Csicsvari J, Jamieson B, Wise KD, Buzsáki G (2003) Mechanisms of gamma oscillations in the hippocampus of the behaving rat. Neuron 37:311-322.

Daw MI, Tricoire L, Erdelyi F, Szabo G, McBain CJ (2009) Asynchronous transmitter release from cholecystokinin-containing inhibitory interneurons is widespread and target-cell independent. J Neurosci 29:1111211122 .

DeFelipe J (2015) The anatomical problem posed by brain complexity and size: a potential solution. Front Neuroanat 9:104.

Destexhe A, Paré D (1999) Impact of network activity on the integrative properties of neocortical pyramidal neurons in vivo. J Neurophysiol 81:1531-1547.

Deuchars J, Thomson AM (1996) CA1 pyramid-pyramid connections in rat hippocampus in vitro: dual intracellular recordings with biocytin filling. Neuroscience 74:1009-1018.

Dhillon A, Jones RS (2000) Laminar differences in recurrent excitatory transmission in the rat entorhinal cortex in vitro. Neuroscience 99:413-422.

Ekstrom AD, Kahana MJ, Caplan JB, Fields TA, Isham EA, Newman EL, Fried I (2003) Cellular networks underlying human spatial navigation. Nature 425:184-188.

Erö C, Gewaltig MO, Keller D, Markram H (2018) A cell atlas for the mouse brain. Front Neuroinform 12:84.

Farhoodi R, Lansdell BJ, Kording KP (2019) Quantifying how staining methods bias measurements of neuron morphologies. Front Neuroinform $13: 36$.
Ferraguti F, Klausberger T, Cobden P, Baude A, Roberts JD, Szucs P, Kinoshita A, Shigemoto R, Somogyi P, Dalezios Y (2005) Metabotropic glutamate receptor 8-expressing nerve terminals target subsets of GABAergic neurons in the hippocampus. J Neurosci 25:10520-10536.

Ferrante M, Migliore M, Ascoli GA (2013) Functional impact of dendritic branch-point morphology. J Neurosci 33:2156-2165.

Ferrante M, Tahvildari B, Duque A, Hadzipasic M, Salkoff D, Zagha EW, Hasselmo ME, McCormick DA (2016) Distinct functional groups emerge from the intrinsic properties of molecularly identified entorhinal interneurons and principal cells. Cereb Cortex 27:3186-3207.

Freund TF, Buzsáki G (1996) Interneurons of the hippocampus. Hippocampus 6:347-470.

Freund TF, Katona I (2007) Perisomatic Inhibition. Neuron 56:33-42.

Fuchs EC, Zivkovic AR, Cunningham MO, Middleton S, Lebeau FE, Bannerman DM, Rozov A, Whittington MA, Traub RD, Rawlins JN, Monyer H (2007) Recruitment of parvalbumin-positive interneurons determines hippocampal function and associated behavior. Neuron 53:591-604.

Fuentealba P, Begum R, Capogna M, Jinno S, Márton LF, Csicsvari J, Thomson A, Somogyi P, Klausberger T (2008a) Ivy cells: a population of nitric-oxide-producing, slow-spiking GABAergic neurons and their involvement in hippocampal network activity. Neuron 57:917-929.

Fuentealba P, Tomioka R, Dalezios Y, Márton LF, Studer M, Rockland K, Klausberger T, Somogyi P (2008b) Rhythmically active enkephalinexpressing GABAergic cells in the CA1 area of the hippocampus project to the subiculum and preferentially innervate interneurons. J Neurosci 28:10017-10022.

Fuentealba P, Klausberger T, Karayannis T, Suen WY, Huck J, Tomioka R, Rockland K, Capogna M, Studer M, Morales M, Somogyi P (2010) Expression of COUP-TFII nuclear receptor in restricted GABAergic neuronal populations in the adult rat hippocampus. J Neurosci 30:15951609.

Fukuda T, Kosaka T (2000) Gap junctions linking the dendritic network of GABAergic interneurons in the hippocampus. J Neurosci 20:1519-1528.

Ganter P, Szücs P, Paulsen O, Somogyi P (2004) Properties of horizontal axo-axonic cells in stratum oriens of the hippocampal CA1 area of rats in vitro. Hippocampus 14:232-243.

Garden DL, Dodson PD, O’Donnell C, White MD, Nolan MF (2008) Tuning of synaptic integration in the medial entorhinal cortex to the organization of grid cell firing fields. Neuron 60:875-889.

Glickfeld LL, Scanziani M (2006) Distinct timing in the activity of cannabinoid-sensitive and cannabinoid-insensitive basket cells. Nat Neurosci 9:807-815.

Gloveli T, Dugladze T, Schmitz D, Heinemann U (2001) Properties of entorhinal cortex deep layer neurons projecting to the rat dentate gyrus. Eur J Neurosci 13:413-420.

Gloveli T, Dugladze T, Rotstein HG, Traub RD, Monyer H, Heinemann U, Whittington MA, Kopell NJ (2005a) Orthogonal arrangement of rhythm-generating microcircuits in the hippocampus. Proc Natl Acad Sci USA 102:13295-13300.

Gloveli T, Dugladze T, Saha S, Monyer H, Heinemann U, Traub RD, Whittington MA, Buhl EH (2005b) Differential involvement of oriens/ pyramidale interneurones in hippocampal network oscillations in vitro. J Physiol 562:131-147.

Golding NL, Mickus T, Katz Y, Kath WL, Spruston N (2005) Factors mediating powerful voltage attenuation along CA1 pyramidal neuron dendrites. J Physiol 568:69-82.

Gould E, Woolley CS, Frankfurt M, McEwen BS (1990) Gonadal steroids regulate dendritic spine density in hippocampal pyramidal cells in adulthood. J Neurosci 10:1286-1291.

Grillo FW, Neves G, Walker A, Vizcay-Barrena G, Fleck RA, Branco T, Burrone J (2018) A distance-dependent distribution of presynaptic boutons tunes frequency-dependent dendritic integration. Neuron 99:275282.e3.

Gulyás AI, Miles R, Hájos N, Freund TF (1993) Precision and variability in postsynaptic target selection of inhibitory cells in the hippocampal CA3 region. Eur J Neurosci 5:1729-1751.

Gulyás AI, Hájos N, Freund TF (1996) Interneurons containing calretinin are specialized to control other interneurons in the rat hippocampus. J Neurosci 16:3397-3411.

Gulyás AI, Szabó GG, Ulbert I, Holderith N, Monyer H, Erdélyi F, Szabó G, Freund TF, Hájos N (2010) Parvalbumin-containing fast-spiking basket 
cells generate the field potential oscillations induced by cholinergic receptor activation in the hippocampus. J Neurosci 30:15134-15145.

Gupta A, Elgammal FS, Proddutur A, Shah S, Santhakumar V (2012) Decrease in tonic inhibition contributes to increase in dentate semilunar granule cell excitability after brain injury. J Neurosci 32:2523-2537.

Guzman L, Commandeur F, Acosta O, Simon A, Fautrel A, Rioux-Leclercq N, Romero E, Mathieu R, de Crevoisier R (2016) Slice correspondence estimation using SURF descriptors and context-based search for prostate whole-mount histology MRI registration. Annual International Conference of the IEEE Engineering in Medicine and Biology Society, pp 1163-1166.

Hájos N, Mody I (1997) Synaptic communication among hippocampal interneurons: properties of spontaneous IPSCs in morphologically identified cells. J Neurosci 17:8427-8442.

Hájos N, Papp EC, Acsády L, Levey A, Freund T (1998) Distinct interneuron types express $\mathrm{m} 2$ muscarinic receptor immunoreactivity on their dendrites or axon terminals in the hippocampus. Neuroscience 82:355-376.

Hájos N, Pálhalmi J, Mann EO, Németh B, Paulsen O, Freund TF (2004) Spike timing of distinct types of GABAergic interneuron during hippocampal gamma oscillations in vitro. J Neurosci 24:9127-9137.

Hájos N, Karlócai MR, Németh B, Ulbert I, Monyer H, Szabó G, Erdelyi F, Freund TF, Gulyás AI (2013) Input-output features of anatomically identified CA3 neurons during hippocampal sharp wave/ripple oscillation in vitro. J Neurosci 33:11677-11691.

Halasy K, Somogyi P (1993) Subdivisions in the multiple GABAergic innervation of granule cells in the dentate gyrus of the rat hippocampus. Eur J Neurosci 5:411-429.

Halasy K, Buhl EH, Lörinczi Z, Tamás G, Somogyi P (1996) Synaptic target selectivity and input of GABAergic basket and bistratified interneurons in the CA1 area of the rat hippocampus. Hippocampus 6:306-329.

Hamam BN, Kennedy TE, Alonso A, Amaral DG (2000) Morphological and electrophysiological characteristics of layer $\mathrm{V}$ neurons of the rat medial entorhinal cortex. J Comp Neurol 418:457-472.

Hamam BN, Amaral DG, Alonso AA (2002) Morphological and electrophysiological characteristics of layer $\mathrm{V}$ neurons of the rat lateral entorhinal cortex. J Comp Neurol 451:45-61.

Hamilton DJ, Wheeler DW, White CM, Rees CL, Komendantov AO, Bergamino M, Ascoli GA (2017) Name-calling in the hippocampus (and beyond): coming to terms with neuron types and properties. Brain Inform $4: 1-12$.

Han ZS, Buhl EH, Lörinczi Z, Somogyi P (1993) A high degree of spatial selectivity in the axonal and dendritic domains of physiologically identified local-circuit neurons in the dentate gyms of the rat hippocampus. Eur J Neurosci 5:395-410.

Harris E, Witter MP, Weinstein G, Stewart M (2001) Intrinsic connectivity of the rat subiculum: I. Dendritic morphology and patterns of axonal arborization by pyramidal neurons. J Comp Neurol 435:490-505.

Harris KM, Stevens JK (1989) Dendritic spines of CA 1 pyramidal cells in the rat hippocampus: serial electron microscopy with reference to their biophysical characteristics. J Neurosci 9:2982-2997.

Herculano-Houzel S, Ribeiro P, Campos L, Valotta da Silva A, Torres LB, Catania KC, Kaas JH (2011) Updated neuronal scaling rules for the brains of glires (rodents/lagomorphs). Brain Behav Evol 78:302-314.

Hosp JA, Strüber M, Yanagawa Y, Obata K, Vida I, Jonas P, Bartos M (2014) Morpho-physiological criteria divide dentate gyrus interneurons into classes. Hippocampus 24:189-203.

Ishizuka N, Weber J, Amaral DG (1990) Organization of intrahippocampal projections originating from CA3 pyramidal cells in the rat. J Comp Neurol 295:580-623.

Ishizuka N, Cowan WM, Amaral DG (1995) A quantitative analysis of the dendritic organization of pyramidal cells in the rat hippocampus. J Comp Neurol 362:17-45.

Ixmatlahua DJ, Vizcarra B, Gómez-Lira G, Romero-Maldonado I, Ortiz F, Rojas-Piloni G, Gutiérrez R (2020) Neuronal glutamatergic network electrically wired with silent but activatable gap junctions. J Neurosci 40:4661-4672.

Jensen O, Kaiser J, Lachaux JP (2007) Human gamma-frequency oscillations associated with attention and memory. Trends Neurosci 30:317-324.

Jiang X, Shen S, Cadwell CR, Berens P, Sinz F, Ecker AS, Patel S, Tolias AS (2015) Principles of connectivity among morphologically defined cell types in adult neocortex. Science 350:aac9462.
Juárez I, Gratton A, Flores G (2008) Ontogeny of altered dendritic morphology in the rat prefrontal cortex, hippocampus, and nucleus accumbens following Cesarean delivery and birth anoxia. J Comp Neurol 507:17341747.

Kamsu JM, Constans JM, Lamberton F, Courtheoux P, Denise P, Philoxene B, Coquemont M, Besnard S (2013) Structural layers of ex vivo rat hippocampus at 7T MRI. PLoS One 8:e76135.

Karayannis T, Elfant D, Huerta-Ocampo I, Teki S, Scott RS, Rusakov DA, Jones MV, Capogna M (2010) Slow GABA transient and receptor desensitization shape synaptic responses evoked by hippocampal neurogliaform cells. J Neurosci 30:9898-9909.

Kelsch W, Li Z, Wieland S, Senkov O, Herb A, Göngrich C, Monyer H (2014) GluN2B-containing NMDA receptors promote glutamate synapse development in hippocampal interneurons. J Neurosci 34:16022-16030.

Kinnavane L, Vann SD, Nelson AJ, O’Mara SM, Aggleton JP (2018) Collateral projections innervate the mammillary bodies and retrosplenial cortex: a new category of hippocampal cells. eNeuro 5:ENEURO.038317.2018.

Kirson ED, Yaari Y (2000) Unique properties of NMDA receptors enhance synaptic excitation of radiatum giant cells in rat hippocampus. J Neurosci 20:4844-4854.

Kispersky TJ, Fernandez FR, Economo MN, White JA (2012) Spike resonance properties in hippocampal O-LM cells are dependent on refractory dynamics. J Neurosci 32:3637-3651.

Kjonigsen LJ, Lillehaug S, Bjaalie JG, Witter MP, Leergaard TB (2015) Waxholm Space atlas of the rat brain hippocampal region: three-dimensional delineations based on magnetic resonance and diffusion tensor imaging. Neuroimage 108:441-449.

Klausberger T (2009) GABAergic interneurons targeting dendrites of pyramidal cells in the CA1 area of the hippocampus. Eur J Neurosci 30:947957.

Klausberger T, Somogyi P (2008) Neuronal diversity and temporal dynamics: the unity of hippocampal circuit operations. Science 321:53-57.

Klausberger T, Márton LF, Baude A, Roberts JD, Magill PJ, Somogyi P (2004) Spike timing of dendrite-targeting bistratified cells during hippocampal network oscillations in vivo. Nat Neurosci 7:41-47.

Klausberger T, Marton LF, O'Neill J, Huck JH, Dalezios Y, Fuentealba P, Suen WY, Papp E, Kaneko T, Watanabe M, Csicsvari J, Somogyi P (2005) Complementary roles of cholecystokinin- and parvalbumin-expressing GABAergic neurons in hippocampal network oscillations. J Neurosci 25:9782-9793.

Kohara K, Pignatelli M, Rivest AJ, Jung HY, Kitamura T, Suh J, Frank D, Kajikawa K, Mise N, Obata Y, Wickersham IR, Tonegawa S (2014) Cell type-specific genetic and optogenetic tools reveal hippocampal CA2 circuits. Nat Neurosci 17:269-279.

Komendantov AO, Venkadesh S, Rees CL, Wheeler DW, Hamilton DJ, Ascoli GA (2019) Quantitative firing pattern phenotyping of hippocampal neuron types. Sci Rep 9:17915.

Kowalski J, Geuting M, Paul S, Dieni S, Laurens J, Zhao S, Drakew A, Haas CA, Frotscher M, Vida I (2010) Proper layering is important for precisely timed activation of hippocampal mossy cells. Cereb Cortex 20:20432054.

Lapray D, Lasztoczi B, Lagler M, Viney TJ, Katona L, Valenti O, Hartwich K, Borhegyi Z, Somogyi P, Klausberger T (2012) Behavior-dependent specialization of identified hippocampal interneurons. Nat Neurosci 15:1265-1271.

Leão RN, Mikulovic S, Leão KE, Munguba H, Gezelius H, Enjin A, Patra K, Eriksson A, Loew LM, Tort AB, Kullander K (2012) OLM interneurons differentially modulate $\mathrm{CA} 3$ and entorhinal inputs to hippocampal CA1 neurons. Nat Neurosci 15:1524-1530.

Lee SH, Földy C, Soltesz I (2010) Distinct endocannabinoid control of GABA release at perisomatic and dendritic synapses in the hippocampus. J Neurosci 30:7993-8000

Lee SY, Földy C, Szabadics J, Soltesz I (2011) Cell-type-specific CCK2 receptor signaling underlies the cholecystokinin-mediated selective excitation of hippocampal parvalbumin-positive fast-spiking basket cells. J Neurosci 31:10993-11002.

Lee T, Jarome T, Li SJ, Kim JJ, Helmstetter FJ (2009) Chronic stress selectively reduces hippocampal volume in rats: a longitudinal magnetic resonance imaging study. Neuroreport 20:1554-1558. 
Li D, Field PM, Starega U, Li Y, Raisman G (1993) Entorhinal axons project to dentate gyrus in organotypic slice co-culture. Neuroscience 52:799813.

Liu YC, Cheng JK, Lien CC (2014) Rapid dynamic changes of dendritic inhibition in the dentate gyrus by presynaptic activity patterns. J Neurosci 34:1344-1357.

Longair MH, Baker D, Armstrong JD (2011) Simple neurite tracer: open source software for reconstruction, visualization and analysis of neuronal processes. Bioinformatics 27:2453-2454.

Losonczy A, Zhang L, Shigemoto R, Somogyi P, Nusser Z (2002) Cell type dependence and variability in the short-term plasticity of EPSCs in identified mouse hippocampal interneurones. J Physiol 542:193-210.

Lübke J, Frotscher M, Spruston N (1998) Specialized electrophysiological properties of anatomically identified neurons in the hilar region of the rat fascia dentata. J Neurophysiol 79:1518-1534.

Maccaferri G (2005) Stratum oriens horizontal interneurone diversity and hippocampal network dynamics. J Physiol 562:73-80.

Maccaferri G, McBain CJ (1996) Long-term potentiation in distinct subtypes of hippocampal nonpyramidal neurons. J Neurosci 16:5334-5343.

Maccaferri G, David J, Roberts B, Szucs P, Cottingham CA, Somogyi P (2000) Cell surface domain specific postsynaptic currents evoked by identified GABAergic neurones in rat hippocampus in vitro. J Physiol 524:91-116.

Magee JC (1998) Dendritic hyperpolarization-activated currents modify the integrative properties of hippocampal CA1 pyramidal neurons. J Neurosci 18:7613-7624.

Markwardt SJ, Dieni CV, Wadiche JI, Overstreet-Wadiche L (2011) Ivy/neurogliaform interneurons coordinate activity in the neurogenic niche. Nat Neurosci 14:1407-1409.

Martina M, Vida I, Jonas P (2000) Distal initiation and active propagation of action potentials in interneuron dendrites. Science 287:295-300.

Martínez A, Lübke J, Del Río JA, Soriano E, Frotscher M (1996) Regional variability and postsynaptic targets of chandelier cells in the hippocampal formation of the rat. J Comp Neurol 376:28-44.

Masurkar AV, Srinivas KV, Brann DH, Warren R, Lowes DC, Siegelbaum SA (2017) Medial and lateral entorhinal cortex differentially excite deep versus superficial CA1 pyramidal neurons. Cell Rep 18:148-160.

Mátyás F, Freund TF, Gulyás AI (2004) Convergence of excitatory and inhibitory inputs onto CCK-containing basket cells in the CA1 area of the rat hippocampus. Eur J Neurosci 19:1243-1256.

McBain CJ, DiChiara TJ, Kauer JA (1994) Activation of metabotropic glutamate receptors differentially affects two classes of hippocampal interneurons and potentiates excitatory synaptic transmission. J Neurosci 14:44334445.

McQuiston AR, Madison DV (1999) Muscarinic receptor activity has multiple effects on the resting membrane potentials of CA1 hippocampal interneurons. J Neurosci 19:5693-5702.

Megías M, Emri Z, Freund TF, Gulyás AI (2001) Total number and distribution of inhibitory and excitatory synapses on hippocampal CA1 pyramidal cells. Neuroscience 102:527-540.

Menendez de la Prida L, Suarez F, Pozo MA (2003) Electrophysiological and morphological diversity of neurons from the rat subicular complex in vitro. Hippocampus 13:728-744.

Mercer A, Trigg HL, Thomson AM (2007) Characterization of neurons in the CA2 subfield of the adult rat hippocampus. J Neurosci 27:7329-7338.

Mercer A, Botcher NA, Eastlake K, Thomson AM (2012) SP-SR interneurones: a novel class of neurones of the CA2 region of the hippocampus. Hippocampus 22:1758-1769.

Middleton S, Jalics J, Kispersky T, Lebeau FE, Roopun AK, Kopell NJ, Whittington MA, Cunningham MO (2008) NMDA receptor-dependent switching between different gamma rhythm-generating microcircuits in entorhinal cortex. Proc Natl Acad Sci USA 105:18572-18577.

Mishchenko Y, Hu T, Spacek J, Mendenhall J, Harris KM, Chklovskii DB (2010) Ultrastructural analysis of hippocampal neuropil from the connectomics perspective. Neuron 67:1009-1020.

Moradi K, Ascoli GA (2020) A comprehensive knowledge base of synaptic electrophysiology in the rodent hippocampal formation. Hippocampus 30:314-331.

Moser MB, Trommald M, Andersen P (1994) An increase in dendritic spine density on hippocampal CA1 pyramidal cells following spatial learning in adult rats suggests the formation of new synapses. Proc Natl Acad Sci USA 91:12673-12675.
Mott DD, Turner DA, Okazaki MM, Lewis DV (1997) Interneurons of the dentate-hilus border of the rat dentate gyrus: morphological and electrophysiological heterogeneity. J Neurosci 17:3990-4005.

Murakami TC, Mano T, Saikawa S, Horiguchi SA, Shigeta D, Baba K, Sekiya H, Shimizu Y, Tanaka KF, Kiyonari H, Iino M, Mochizuki H, Tainaka K, Ueda HR (2018) A three-dimensional single-cell-resolution whole-brain atlas using CUBIC-X expansion microscopy and tissue clearing. Nat Neurosci 21:625-637.

Nelson S, Chris M (2006) Structural and functional properties of hippocampal neurons. In: The hippocampus book. Oxford: Oxford UP.

Nilssen ES, Jacobsen B, Fjeld G, Nair RR, Blankvoort S, Kentros C, Witter MP (2018) Inhibitory connectivity dominates the fan cell network in layer II of lateral entorhinal cortex. J Neurosci 38:9712-9727.

Oliva AA, Jiang M, Lam T, Smith KL, Swann JW (2000) Novel hippocampal interneuronal subtypes identified using transgenic mice that express green fluorescent protein in GABAergic interneurons. J Neurosci 20:3354-3368.

Papa M, Segal M (1996) Morphological plasticity in dendritic spines of cultured hippocampal neurons. Neuroscience 71:1005-1011.

Parekh R, Armañanzas R, Ascoli GA (2015) The importance of metadata to assess information content in digital reconstructions of neuronal morphology. Cell Tissue Res 360:121-127.

Patton PE, McNaughton B (1995) Connection matrix of the hippocampal formation: I. The dentate gyrus. Hippocampus 5:245-286.

Pawelzik H, Hughes DI, Thomson AM (2002) Physiological and morphological diversity of immunocytochemically defined parvalbumin- and cholecystokinin-positive interneurones in CA1 of the adult rat hippocampus. J Comp Neurol 443:346-367.

Pelkey KA, Chittajallu R, Craig MT, Tricoire L, Wester JC, McBain CJ (2017) Hippocampal GABAergic inhibitory interneurons. Physiol Rev 97:16191747.

Peters A, Feldman ML (1976) The projection of the lateral geniculate nucleus to area 17 of the rat cerebral cortex: I. General description. J Neurocytol 5:63-84.

Pierce JP, McCloskey DP, Scharfman HE (2011) Morphometry of hilar ectopic granule cells in the rat. J Comp Neurol 519:1196-1218.

Price CJ, Cauli B, Kovacs ER, Kulik A, Lambolez B, Shigemoto R, Capogna M (2005) Neurogliaform neurons form a novel inhibitory network in the hippocampal CA1 area. J Neurosci 25:6775-6786.

Quattrocolo G, Maccaferri G (2014) Optogenetic activation of Cajal-Retzius cells reveals their glutamatergic output and a novel feedforward circuit in the developing mouse hippocampus. J Neurosci 34:13018-13032.

Quilichini P, Sirota A, Buzsáki G (2010) Intrinsic circuit organization and theta-gamma oscillation dynamics in the entorhinal cortex of the rat. J Neurosci 30:11128-11142.

Rama S, Zbili M, Debanne D (2018) Signal propagation along the axon. Curr Opin Neurobiol 51:37-44.

Rapp PR, Stack EC, Gallagher M (1999) Morphometric studies of the aged hippocampus: I. Volumetric analysis in behaviorally characterized rats. J Comp Neurol 403:459-470.

Rees CL, Moradi K, Ascoli GA (2017) Weighing the evidence in Peters' rule: does neuronal morphology predict connectivity? Trends Neurosci 40:63-71.

Rees CL, Wheeler DW, Hamilton DJ, White CM, Komendantov AO, Ascoli GA (2016) Graph theoretic and motif analyses of the hippocampal neuron type potential connectome. eNeuro 3:ENEURO.0205-16.2016.

Ropireddy D, Ascoli G (2011) Potential synaptic connectivity of different neurons onto pyramidal cells in a $3 \mathrm{D}$ reconstruction of the rat hippocampus. Front Neuroinform 5:5.

Ropireddy D, Bachus SE, Ascoli GA (2012) Non-homogeneous stereological properties of the rat hippocampus from high-resolution 3D serial reconstruction of thin histological sections. Neuroscience 205:91-111.

Schmidt H, Gour A, Straehle J, Boergens KM, Brecht M, Helmstaedter M (2017) Axonal synapse sorting in medial entorhinal cortex. Nature 549:469-475.

Schmidt-Hieber C, Toleikyte G, Aitchison L, Roth A, Clark BA, Branco T, Häusser M (2017) Active dendritic integration as a mechanism for robust and precise grid cell firing. Nat Neurosci 20:1114-1121.

Scorcioni R, Ascoli GA (2005) Algorithmic reconstruction of complete axonal arborizations in rat hippocampal neurons. Neurocomputing $65: 15-22$. 
Scorcioni R, Lazarewicz MT, Ascoli GA (2004) Quantitative morphometry of hippocampal pyramidal cells: differences between anatomical classes and reconstructing laboratories. J Comp Neurol 473:177-193.

Sik A, Ylinen A, Penttonen M, Buzsaki G (1994) Inhibitory CA1-CA3-hilar region feedback in the hippocampus. Science 265:1722-1724.

Sik A, Penttonen M, Buzsáki G (1997) Interneurons in the hippocampal dentate gyrus: an in vivo intracellular study. Eur J Neurosci 9:573-588.

Sohal VS, Zhang F, Yizhar O, Deisseroth K (2009) Parvalbumin neurons and gamma rhythms enhance cortical circuit performance. Nature 459:698702 .

Somogyi P, Klausberger T (2005) Defined types of cortical interneurone structure space and spike timing in the hippocampus. J Physiol 562:9-26.

Soriano E, Martinez A, Farińas I, Frotscher M (1993) Chandelier cells in the hippocampal formation of the rat: the entorhinal area and subicular complex. J Comp Neurol 337:151-167.

Sousa N, Paula-Barbosa M, Almeida OF (1999) Ligand and subfield specificity of corticoid-induced neuronal loss in the rat hippocampal formation. Neuroscience 89:1079-1087.

Spruston N, Lübke J, Frotscher M (1997) Interneurons in the stratum lucidum of the rat hippocampus: an anatomical and electrophysiological characterization. J Comp Neurol 385:427-440.

Spruston N, McBain C (2007) Structural and functional properties of hippocampal neurons. In: The hippocampus book. Oxford: Oxford UP.

Stepanyants A, Hof PR, Chklovskii DB (2002) Geometry and structural plasticity of synaptic connectivity. Neuron 34:275-288.

Stepanyants A, Tamás G, Chklovskii DB (2004) Class-specific features of neuronal wiring. Neuron 43:251-259.

Sugino K, Clark E, Schulmann A, Shima Y, Wang L, Hunt DL, Hooks BM, Tränkner D, Chandrashekar J, Picard S, Lemire AL, Spruston N, Hantman AW, Nelson SB (2019) Mapping the transcriptional diversity of genetically and anatomically defined cell populations in the mouse brain. Elife 8:e38619.

Sun Q, Srinivas KV, Sotayo A, Siegelbaum SA (2014) Dendritic $\mathrm{Na}^{+}$spikes enable cortical input to drive action potential output from hippocampal CA2 pyramidal neurons. Elife 3:e04551.

Sunanda MSR, Raju TR (1995) Effect of chronic restraint stress on dendritic spines and excrescences of hippocampal CA3 pyramidal neurons-a quantitative study. J Neurosci 19:85-95.

Svoboda KR, Adams CE, Lupica CR (1999) Opioid receptor subtype expression defines morphologically distinct classes of hippocampal interneurons. J Neurosci 19:85-95.

Szabadics J, Soltesz I (2009) Functional specificity of mossy fiber innervation of GABAergic cells in the hippocampus. J Neurosci 29:4239-4251.

Szabadics J, Varga C, Brunner J, Chen K, Soltesz I (2010) Granule cells in the CA3 area. J Neurosci 30:8296-8307.

Szabó GG, Holderith N, Gulyás AI, Freund TF, Hájos N (2010) Distinct synaptic properties of perisomatic inhibitory cell types and their different modulation by cholinergic receptor activation in the CA3 region of the mouse hippocampus. Eur J Neurosci 31:2234-2246.

Szabó GG, Papp OI, Máté Z, Szabó G, Hájos N (2014) Anatomically heterogeneous populations of $\mathrm{CB} 1$ cannabinoid receptor-expressing interneurons in the CA3 region of the hippocampus show homogeneous inputoutput characteristics. Hippocampus 24:1506-1523.

Takács VT, Klausberger T, Somogyi P, Freund TF, Gulyás AI (2012) Extrinsic and local glutamatergic inputs of the rat hippocampal CA1 area differentially innervate pyramidal cells and interneurons. Hippocampus 22:1379-1391.

Tahvildari B, Alonso A (2005) Morphological and electrophysiological properties of lateral entorhinal cortex layers II and III principal neurons. J Comp Neurol 491:123-140

Tahvildari B, Wölfel M, Duque A, McCormick DA (2012) Selective functional interactions between excitatory and inhibitory cortical neurons and differential contribution to persistent activity of the slow oscillation. J Neurosci 32:12165-12179.

Tricoire L, Pelkey KA, Daw MI, Sousa VH, Miyoshi G, Jeffries B, Cauli B, Fishell G, McBain CJ (2010) Common origins of hippocampal ivy and nitric oxide synthase expressing neurogliaform cells. J Neurosci 30:21652176.

Tricoire L, Pelkey KA, Erkkila BE, Jeffries BW, Yuan X, McBain CJ (2011) A blueprint for the spatiotemporal origins of mouse hippocampal interneuron diversity. J Neurosci 31:10948-10970.
Tukker JJ, Fuentealba P, Hartwich K, Somogyi P, Klausberger T (2007) Cell type-specific tuning of hippocampal interneuron firing during gamma oscillations in vivo. J Neurosci 27:8184-8189.

Tyan L, Chamberland S, Magnin E, Camiré O, Francavilla R, David LS, Deisseroth K, Topolnik L (2014) Dendritic inhibition provided by interneuron-specific cells controls the firing rate and timing of the hippocampal feedback inhibitory circuitry. J Neurosci 34:4534-4547.

Uylings HB, Ruiz-Marcos A, van Pelt J (1986) The metric analysis of threedimensional dendritic tree patterns: a methodological review. J Neurosci Methods 18:127-151.

van Strien NM, Cappaert NL, Witter MP (2009) The anatomy of memory: an interactive overview of the parahippocampal-hippocampal network. Nat Rev Neurosci 10:272-282.

Varga C, Oijala M, Lish J, Szabo GG, Bezaire M, Marchionni I, Golshani P, Soltesz I (2014) Functional fission of parvalbumin interneuron classes during fast network events. Elife 3:e04006.

Venkadesh S, Komendantov AO, Wheeler DW, Hamilton DJ, Ascoli GA (2019) Simple models of quantitative firing phenotypes in hippocampal neurons: comprehensive coverage of intrinsic diversity. PLOS Comput Biol 15:e1007462.

Vida I (2010) Morphology of hippocampal neurons. In Hippocampal microcircuits: a computational modeler's resource book (Cutsuridis V, Graham B, Cobb S, Vida I, eds). Springer pp 27-67. ISBN 978-1-4419-0995-4.

Vida I, Frotscher M (2000) A hippocampal interneuron associated with the mossy fiber system. Proc Natl Acad Sci USA 97:1275-1280.

Wagner T, Lipinski H (2013) IJBlob: an ImageJ library for connected component analysis and shape analysis. J Open Res Softw 1:e6.

West MJ, Danscher G, Gydesen H (1978) A determination of the volumes of the layers of the rat hippocampal region. Cell Tissue Res 188:345-359.

Wheeler DW, White CM, Rees CL, Komendantov AO, Hamilton DJ, Ascoli GA (2015) Hippocampome.org: a knowledge base of neuron types in the rodent hippocampus. Elife 4:e09960.

White CM, Rees CL, Wheeler DW, Hamilton DJ, Ascoli GA (2020) Molecular expression profiles of morphologically defined hippocampal neuron types: empirical evidence and relational inferences. Hippocampus 30:472-487.

Winnubst J, Bas E, Ferreira TA, Wu Z, Economo MN, Edson P, Arthur BJ, Bruns C, Rokicki K, Schauder D, Olbris DJ, Murphy SD, Ackerman DG, Arshadi C, Baldwin P, Blake R, Elsayed A, Hasan M, Ramirez D, Dos Santos B, et al. (2019) Reconstruction of 1,000 projection neurons reveals new cell types and organization of long-range connectivity in the mouse brain. Cell 179:268-281.e13

Witter MP (2006) Connections of the subiculum of the rat: topography in relation to columnar and laminar organization. Behav Brain Res 174:251-264.

Witter MP, Doan TP, Jacobsen B, Nilssen ES, Ohara S (2017) Architecture of the entorhinal cortex: a review of entorhinal anatomy in rodents with some comparative notes. Front Syst Neurosci 11:46.

Wolf O, Dyakin V, Vadasz C, de Leon M, McEwen B, Bulloch K (2002) Volumetric measurement of the hippocampus, the anterior cingulate cortex, and the retrosplenial granular cortex of the rat using structural MRI. Brain Res Brain Res Protoc 10:41-46.

Xiong G, Metheny H, Johnson BN, Cohen AS (2017) A comparison of different slicing planes in preservation of major hippocampal pathway fibers in the mouse. Front Neuroanat 11:107.

Yang S, Yang S, Moreira T, Hoffman G, Carlson GC, Bender KJ, Alger BE, Tang CM (2014) Interlamellar CA1 network in the hippocampus. Proc Natl Acad Sci USA 111:12919-12924.

Ylinen A, Soltész I, Bragin A, Penttonen M, Sik A, Buzsáki G (1995) Intracellular correlates of hippocampal theta rhythm in identified pyramidal cells, granule cells, and basket cells. Hippocampus 5:78-90.

Yuan M, Meyer T, Benkowitz C, Savanthrapadian S, Ansel-Bollepalli L, Foggetti A, Wulff P, Alcami P, Elgueta C, Bartos M (2017) Somatostatinpositive interneurons in the dentate gyrus of mice provide local- and long-range septal synaptic inhibition. Elife 6:e21105.

Zemankovics R, Káli S, Paulsen O, Freund TF, Hájos N (2010) Differences in subthreshold resonance of hippocampal pyramidal cells and interneurons: the role of h-current and passive membrane characteristics. J Physiol 588:2109-2132 